\title{
Los tranvías en los países del socialismo real de los años 1960 y 1970: de la crisis al impulso
}

\author{
Elvira Khairullina ${ }^{1}$ | Luis Santos y Ganges ${ }^{2}$ \\ Recibido: 01-02-2020 | en su versión final: 04-01-2021
}

Resumen

\begin{abstract}
Después de la Segunda Guerra Mundial, la reconstrucción y el desarrollo del sistema tranviario en los países europeos del socialismo real fue, cuando menos, dubitativo y muy diferenciado. Tanto en Occidente como en Oriente, el automóvil se convirtió en el medio universal de transporte y el Movimiento Moderno triunfó en el urbanismo, de modo que el sistema tranviario se vio como un medio de transporte vetusto e inadaptado, sin futuro. Sin embargo, el impulso industrial y el fuerte crecimiento urbano desde mediados de los años 1960 en los países de régimen comunista, implicó el desarrollo de sistema tranviario, así como la integración de su funcionamiento en el sistema de transporte urbano-suburbano. El objetivo de este artículo de historia urbana y del transporte es dar cuenta del período de renacimiento tranviario en la Europa del socialismo real durante las décadas de 1960 y 1970, con sus contradicciones y problemas, y, en concreto, explicar la implementación del tranvía rápido en sus ciudades. Para mostrarlo, se analizan los planteamientos teóricos y prácticos, así como el propio desarrollo del tranvía, en dos casos diferenciales de estudio: la ciudad checa de Ostrava y la ciudad rusa de Yaroslavl. Se concluye que en los países europeos comunistas hubo una considerable diversidad tanto en la política de transporte público urbano, como en las soluciones de interrelación de transporte y ciudad. Esta investigación ofrece un tema poco estudiado que permite entender mejor la planificación urbana socialista y sus diferencias y similitudes con la experiencia de Europa Occidental.
\end{abstract}

Palabras clave: Tranvía rápido; planificación urbana socialista; transporte público urbano; modelo de movilidad

Citación

\section{Tramways in the Countries of Real Socialism in the 1960s and 1970s: From Crisis to Impetus}

Abstract

\begin{abstract}
After the Second World War, the reconstruction and development of the tramway system in the European countries of real socialism was, at the very least, hesitant, and quite different. Both in the West and in the East, the road became the universal means of transport and the Modern Movement triumphed in urbanism, so that the tramway system was seen as an outdated and unsuitable means of transport. However, the industrial development and strong urban growth since the mid-1960s meant that in the countries of real socialism was necessary: the development of tramway infrastructure and new models of rolling stock, as well as the coordination of their operation in urban-suburban transport system. The aim of this article on urban and transport history is to account for the period of tramway revival in the Europe of real socialism during the 1960s and 1970s, with its contradictions and problems, and to explain the implementation of the rapid tramway in its cities. To this end, the theoretical and practical approaches and the development of the tram itself are analysed in two different case studies: the Czech city Ostrava and the Russian city Yaroslavl. It is concluded that in the European communist countries there was a considerable diversity both in urban public transport policy and in the solutions of interrelation between transport and city. This research offers a barely studied topic that allows a better understanding of socialist urban planning, as well as its differences and similarities with the Western European experience.
\end{abstract}

Keywords: Rapid tramway; socialist city; collective public transport; interrelation transport and city

${ }^{1}$ Arquitecta, Master en Urbanismo, Doctoranda en Historia Urbana Universidad de Valladolid, España (ORCiD: 0000-0003-0004-9704, WoS Researcher ID: AAR-3875-2021), ${ }^{2}$ Geógrafo, Doctor en Urbanismo y Doctor en Historia. Profesor de la Universidad de Valladolid (ORCiD: 0000-0002-0232-7969, WoS Researcher ID: AAQ8172-2020). Correo de contacto: khairullina.es@gmail.com 


\section{Introducción. La ciudad europea y la crisis del tranvía}

Es conocido que desde los años cincuenta del siglo XX tuvo lugar en Occidente una eliminación masiva del tranvía, cuando se materializaba su recuperación económica tras la Segunda Guerra Mundial. Sin embargo, el papel del tranvía en las ciudades empezó a cuestionarse ya desde finales de los años veinte en los países más prósperos, como Estados Unidos, Gran Bretaña y Francia (Yago, 2006; Passalacqua, 2014; Boquet, 2017; Tennant 2017), donde las compañías tranviarias tuvieron poco apoyo público y una competencia muy fuerte de las de autobuses. Entre los años treinta y los años cincuenta, en la mayoría de los países europeos el tranvía continuó teniendo alguna relevancia como medio de transporte urbano (Taplin, 1984; Schmucki, 2010). En la mayoría de las ciudades, el tráfico motorizado aún tenía por entonces un nivel de desarrollo modesto, a pesar de lo cual se fueron imponiendo las ideas del Movimiento Moderno y el desarrollo de su infraestructura viaria. Así, el tranvía fue cuestionado en las ciudades mayores, donde el tráfico automovilístico era notable, además de desarrollarse el metro y plantearse soluciones de tranvía subterráneo. Mientras tanto, en la Unión Soviética de los años treinta, donde el sistema tranviario heredado era menor en comparación con muchos países europeos, este se convirtió en unos de los medios principales de los programas estatales de industrialización (Zilbertal, 1932; Peshekerov, 1936).

Después de la Segunda Guerra Mundial el tranvía entró en un período de incertidumbre y contradicciones en toda Europa, y las clausuras de líneas fueron habituales e incluso masivas (Topp, 1998; Mirás, 2005; Pooley, 2005). Pero no fue así en todos los países europeos: en la República Federal Alemana, Austria, Bélgica y Países Bajos, así como en la República Democrática Alemana (en adelante, RDA), República Socialista Checoeslovaca (en adelante, RSC), Hungría, Polonia y la Unión Soviética (en adelante, URSS), se mantuvieron buena parte de las líneas. Por un lado, las dificultades económicas y la debilidad del desarrollo de la infraestructura viaria y del transporte motorizado permitían que el tranvía supusiese aún en muchas ciudades un importante medio de movilidad urbana. Por otro lado, el tranvía tuvo un papel político importante en la economía de los países socialistas, donde la productividad de las ciudades se relacionaba directamente con la economía nacional. Así, la accesibilidad entre las áreas industriales y las áreas de residencia obrera se convirtió en un asunto primordial (Akademiya Arkhitekturi SSSR, 1956). Con todo, la reconstrucción urbana fue acompañada en la mayor parte de los casos de la reconsideración de los principios de planificación del tráfico y del transporte urbano, entre los que destacaban la racionalización de la estructura urbana mediante la zonificación y la jerarquización de la red viaria. Así, la planificación de la infraestructura viaria basada en una previsión de capacidad sin restricciones se convirtió en la solución principal, también para los países del socialismo real desde finales de los años cincuenta.

Las primeras eliminaciones de líneas tranviarias en los países comunistas se dieron en las áreas centrales y en las calles principales de las ciudades medianas y grandes, donde se entendió que las líneas dificultaban el buen funcionamiento del transporte viario (Polyakov, 1953), así como en las ciudades pequeñas por razones de inviabilidad económica (Archivo Estatal de la República Checa, 1966). En el planeamiento urbanístico de entonces se entendió que el tranvía solo mantenía su eficacia en la conexión urbana de las áreas productivas. Se trató de compactar los flujos de pasajeros y evitar la ramificación de la red tranviaria con el fin de economizar su gestión y de minimizar su interacción con el resto del tráfico. La fluidez y la homogeneidad del tráfico motorizado se convirtió en el criterio principal de la planificación, no solo del transporte sino también de la estructura y la forma urbana.

Estos principios de planificación solo fueron cuestionados ya bien entrados los años sesenta y sobre todo a lo largo de los años setenta, en una coyuntura de fuerte expansión urbana y tras cierto avance técnico en los institutos de planificación, derivado de las nuevas investigaciones teóricas y el análisis de la experiencia anterior en la planificación urbana.

ACE, 16 (4.6) CC BY-ND 3.0 ES | UPC Barcelona, España | Los tranvías en los países del socialismo real de los años 
En este artículo planteamos, pues, lo siguiente: 1) que en los países europeos comunistas ocurrió también una crisis en la consideración funcional y urbana del tranvía pero que duró solo hasta mediados de los años sesenta, 2) esta crisis se resolvió con el desarrollo de nuevas soluciones en transporte público (tranvía rápido y metro ligero), y 3) que en la planificación urbana socialista y en su relación con la planificación del transporte hubo bastante más diversidad de lo que se ha pensado en Occidente. El objetivo de este trabajo es, por lo tanto, desentrañar algo de estas diferencias y sus complejidades en los años sesenta y setenta, seguido con la comparación de dos casos de estudio, Ostrava y Yaroslavl, que entendemos como ciudades medianas representativas de sendos países del socialismo real, la RSC y la URSS. Los planteamientos y las soluciones de su planificación y modernización fueron bastante disímiles, lo que guarda relación con sus diferencias en cuanto a la política estatal de transporte público, la involucración de las autoridades locales, el nivel técnico de formación de los estudios y planes urbanos y de transporte, y la pujanza de los criterios de planificación del tranvía rápido.

\section{Los problemas de tráfico urbano: interrelación de la planificación urbana y la planificación del transporte}

El concepto de "planificación integrada" fue una herramienta de variados usos en los países europeos tanto del Este como del Oeste. Su desarrollo empezó en los años sesenta como una respuesta a los problemas del tráfico automovilístico, al crecimiento urbano rápido y a la complejidad creciente de la estructura urbana (Inoyue, 1966; Hruška, 1966; Mlejnek, 1967; Lehrer, 1969). Para poder organizar el funcionamiento de tráfico de una manera eficiente y con vocación científica se concibió la herramienta del plan general de transporte, separada del plan general urbano. Para ensamblar o articular estos dos planes surgió el nuevo concepto de "planificación integrada". Por planificación integrada se entendió el desarrollo de una visión comprehensiva (objetivos, principios, criterios y métodos de planificación espaciales y organizativos entre varios departamentos y especialistas) sobre los asuntos de transporte y de urbanismo. La necesidad de considerar la relación entre los usos de suelo y la planificación de la infraestructura y del transporte cobró auge con el informe de Colin Buchanan en 1963 (Buchanan, 1963). Para lograr mayor eficiencia en las soluciones a medio y largo plazo, sin abandonar el zoning, debió ser planteado un transporte público más capaz y veloz en relación con el crecimiento urbano, sobre todo en algunos países occidentales como Estados Unidos, Reino Unido o República Federal Alemana (Lehrer, 1961; Leibbrand, 1964; Brown, 1966; Jamieson, 1967; RIBA, 1968). Pero también hubo propuestas sobre el cambio de la política de planificación del tráfico urbano, anunciadas extensivamente en los congresos UITP (Union Internationale des Transports Publics) desde finales de los años sesenta (UITP, 1969; 1975; 1977; 1979).

Cabe señalar que en los países occidentales la planificación integrada se vio limitada por las dificultades de la intervención estatal y la variedad y el peso de los intereses privados, mientras que en los países comunistas hubo ciertamente más control centralizado, con menor capacidad de iniciativa local, aunque ello condujera a algún efecto negativo (Crouch, 1979) como, por ejemplo, en la URSS donde los planes generales de transporte y urbanos fueron realizados por los institutos centrales. Sin embargo, aparte de las grandes diferencias políticas, tanto en un ámbito como en el otro, la organización del trabajo conjunto entre planificadores de transporte y urbanistas fue difícil de lograr. En la práctica no hubo relación entre los planes urbanísticos y de transporte, que requería un esfuerzo adicional para la colaboración entre los planificadores y para la gestión de la ciudad (McGrath, 1973; Hall, 1976). Por un lado, debido a la estanqueidad de las disciplinas y sus normas y administraciones, y, por otro lado, debido a la indefinición de los procesos de toma de decisiones, evaluaciones y control de la integración de planes urbanos y de transporte.

ACE, 16 (4.6) CC BY-ND 3.0 ES | UPC Barcelona, España | Los tranvías en los países del socialismo real de los años 
Por lo que respecta a los países del socialismo real, el objetivo principal fue, en un primer momento, dar solución a las cuestiones urgentes, como la coordinación de los sistemas de transporte urbano y la creación de institutos de investigación y planificación del transporte urbano (Archivo Estatal de Rusia -GARF-, 1963; Archivo Estatal de la República Checa, 1966). En relación con ello, en la RSC se crearon los departamentos locales de planificación del tráfico (Útvar dopravního inženýrství města) desde mediados de los años sesenta, cuya función era la implementación del plan general de transporte de la ciudad. En la URSS no se llegaron a crear departamentos municipales de transporte, de modo que los planes de transporte fueron efectuados por los institutos estatales, como Giprocommundortrans o Autocommundorstroi, aunque a veces también por los institutos estatales de planificación urbana. En cualquier caso, este tipo de planificación dificultaba el óptimo conocimiento de las condiciones locales. Las actuaciones principales de cara a conseguir una planificación integrada se dirigieron a la gestión del funcionamiento coordinado de los sistemas de transporte urbano, aunque la interacción entre planificadores del transporte y urbanistas siguió siendo débil.

En los años setenta se fueron transformando los objetivos de la planificación integrada. Se puso énfasis en la necesidad de planificación a largo plazo, donde debían estar integradas las soluciones de desarrollo de transporte y urbanismo (Archivo Municipal de Ostrava, 1974a), y se vio la necesidad de una mejor organización del proceso de planificación de los planes urbanísticos y los planes de tráfico. El modelo de integración se basó en la realización de estudios y planes preliminares de circulación, como fundamento previo a los planes urbanos. A su vez, estos debían servir para la implementación de los planes generales de transporte, que debían ser aprobados justo después de los planes urbanos. Esta aparente coordinación de planeamiento, sin embargo, en la práctica, supuso de nuevo la prevalencia rotunda del urbanismo de los arquitectos frente a la creciente importancia de la ingeniería de tráfico.

Hubo diferencias enormes en la calidad de los estudios y planes preliminares de tránsito urbano. En la RSC fueron realizados por los institutos estatales de transporte en cooperación con los departamentos locales de planificación urbana y de tráfico. En la URSS, sin embargo, los estudios preliminares de transporte fueron realizados por el instituto estatal de planificación urbana en el transcurso de la formación de los planes generales urbanos. Es decir, los institutos de transporte no se involucraron en la realización de estos estudios de tráfico, sino a lo sumo participaron algunos de sus expertos, lo que finalmente no pudo garantizar la solvencia de las soluciones en materia de transporte público. Así, los estudios soviéticos resultaron superficiales y basados en el mero ajuste del transporte a las condiciones existentes de cada ciudad, sin desplegar alternativas de desarrollo del transporte en relación con las previsiones de desarrollo urbano.

En la URSS y en la RSC, los planes urbanísticos se implementaban para un período de 25-30 años, mientras que los planes generales de transporte se realizaban para un período de 15 años en la URSS y de 10-15 años en la RSC (Bordukov, 1974; VúVA, 1979). Ello parecía facilitar la integración de objetivos y soluciones de desarrollo en materia de urbanística y de transporte. Pero en ambos países ocurrieron desfases importantes en la implementación de sus planes de transporte y de urbanismo. Si bien se relacionaron unos trabajos y otros, el hecho de que los planes de transporte se desarrollasen bastante más tarde que los urbanísticos entorpeció el proceso de expansión urbana. En el caso de la URSS, ello fue agravado a menudo por los cambios introducidos por las autoridades locales (GARF, 1967; Kovalev, 2005). En general, fue un problema común la fuerte dependencia de los planes de tráfico y transporte respecto de los planes urbanos. El modelo de ciudad moderna, la zonificación rígida y las elecciones de morfología urbana siguieron siendo factores decisivos en la toma de decisiones para la circulación urbana. La solución estuvo siempre en manos de los urbanistas, mientras que los planificadores del tráfico apenas pudieron participar en la formación de los planes urbanos, salvo por los estudios previos de desplazamientos.

ACE, 16 (4.6) CC BY-ND 3.0 ES | UPC Barcelona, España | Los tranvías en los países del socialismo real de los años 


\section{El futuro del sistema tranviario desde mediados de los años sesenta ¿tranvía rápido o metro ligero?}

Desde mediados de los años sesenta se potenció el papel de los modos ferroviarios, que demostraban mayor capacidad y velocidad con costes asumibles. Las soluciones comunes en las grandes aglomeraciones de toda Europa fueron el metro y el tren suburbano, que no molestaban al tráfico automovilístico, mientras que no estaba tan claro qué hacer con los tranvías en superficie ni cómo actuar en las ciudades medianas. En algunos países de Europa Occidental, como la república Federal Alemana, Suiza, Suecia, Austria, Bélgica o Países Bajos, tuvo lugar una modernización temprana, en los años cincuenta y sesenta, del material rodante y la infraestructura tranviaria. En estos países se aspiraba a crear un sistema de tranviario transitorio al metro, con sus términos propios como Stadtbahn, Métro léger, Tunnelbana, etc. Se desarrolló al tiempo la infraestructura viaria y los servicios ferroviarios (Hass Klau, 2003). Esto se dio, sobre todo, en las ciudades grandes y medianas, con la financiación del Estado y la involucración de las autoridades locales. A la vez, en otros países occidentales, como Francia, Reino Unido y España, fueron cerrados y desmantelados sus sistemas tranviarios.

Mientras tanto, en los países comunistas, la eliminación de la infraestructura tranviaria fue muy debatida y en parte materializada durante la posguerra, pero desde finales de los años sesenta empezó a ponerse en cuestión (Honzík, 1967; Jansa, 1967; Sheinyuk, 1971, Bolonenkov, 1972). En este cambio de planteamiento intervinieron diferentes factores. Por un lado, se compartía con Occidente la preocupación por el deterioro de la movilidad derivado de la expansión urbana, así como, en menor medida, la preocupación por el deterioro medioambiental. Por otro lado, más que como un asunto social complejo, la problemática del tráfico urbano se entendió como una debilidad económica del sistema, de forma que el gran crecimiento urbano zonificado y el consiguiente incremento de los tiempos de viaje ponían en crisis su visión acerca de la eficacia económica general, por lo que el transporte urbano masivo y rápido debía adquirir mayor relevancia. Aunque, esta idea no fue generalizada ni en todos los países ni, dentro de ellos, en todas las ciudades.

Se puede sostener que hubo disparidad en las políticas tranviarias urbanas en toda Europa durante los años sesenta y setenta. Y no se puede afirmar categóricamente que el tranvía fue un atributo de la "ciudad socialista" ni que no fue desarrollado en los países occidentales. La variedad de opiniones y soluciones no respondió al régimen político, sino a las condiciones políticas, urbanas y culturales de cada país. A pesar de ello, la diferencia clave entre los países occidentales y comunistas fue el relativo mantenimiento de los tranvías en las ciudades medianas de estos últimos, lo que se explica con la eficiencia y la capacidad del tranvía (Hass Klau, Crampton, Benjari, 2004), (Fig. 1).

Desde principios de los años setenta en algunos casos europeos se optó por el desarrollo del metro ligero, mientras que en bastantes casos del Este se optó por el tranvía rápido (Skorostnoit tramvai en la URSS, Schnellstrassenbahn en la RDA y Rychla tramvaje en RSC, mientras que el metro ligero se denominaba Metrotram en la URSS, Stadtbahn en la RDA y Rýchlodráha en la RSC). Aparte de las cuestiones técnicas relativas a estándares tranviarios versus estándares ferroviarios, fue en su momento difícil -y lo es aún hoy- establecer una diferencia clara entre tranvía rápido y metro ligero con relación a su sentido urbano, sobre todo por su versátil funcionalidad práctica, pero lo seguro entonces es que ambas soluciones se basaban en la modernización y ampliación del sistema tranviario existente.

ACE, 16 (4.6) CC BY-ND 3.0 ES | UPC Barcelona, España | Los tranvías en los países del socialismo real de los años 
Figura 1. Comparativa de políticas de tranvía en los países occidentales y socialistas

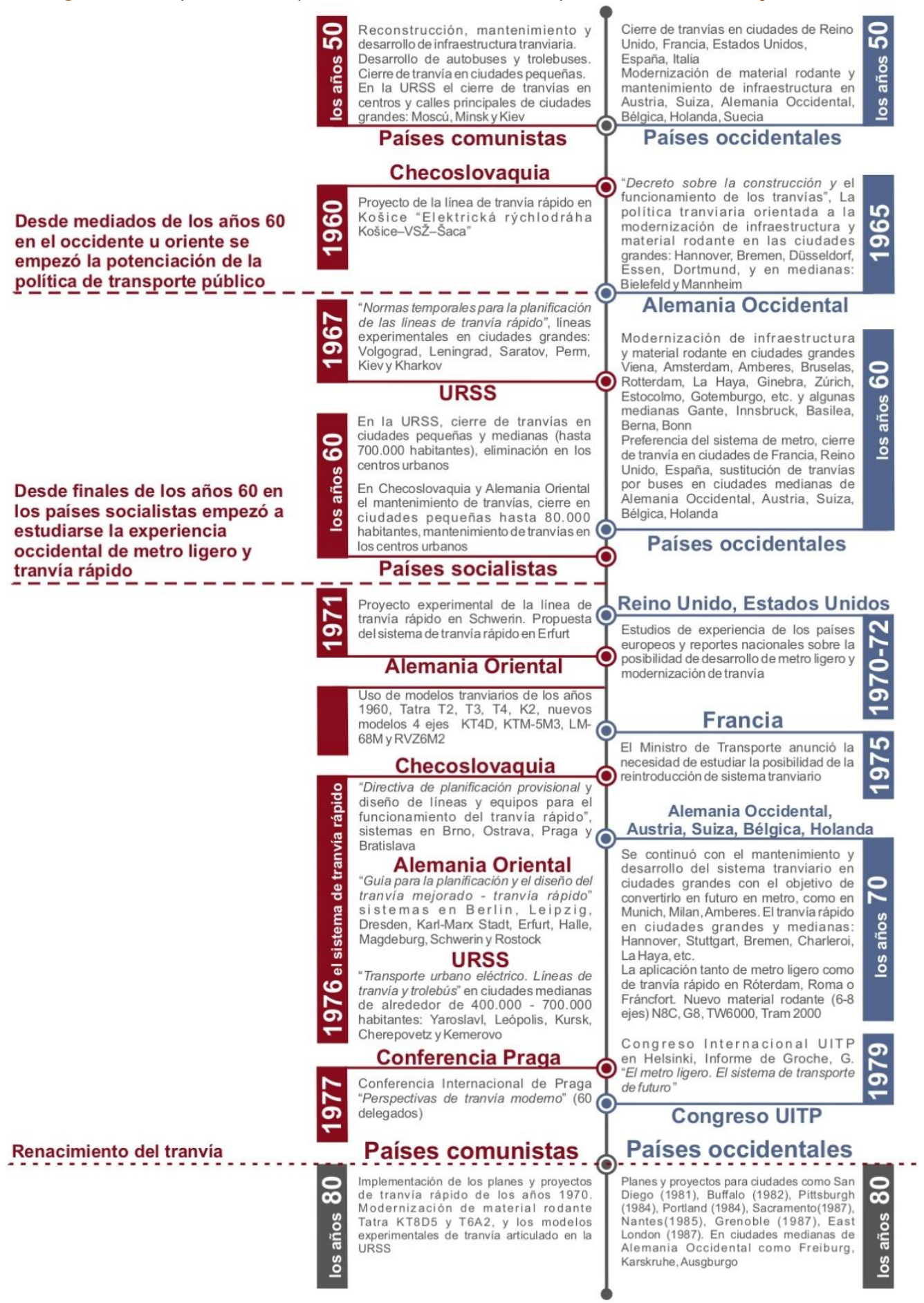

Fuente: Elaboración propia a partir de la lectura de bibliografía histórica y contemporánea.

Los planificadores del transporte urbano de aquel período coincidieron en general en plantear para la modernización tranviaria dos cuestiones. Por un lado, un elevado grado de separación respecto de la infraestructura viaria. Por otro, un diseño de acuerdo con los estándares del tren metropolitano (ancho de vía, radios de giros, altura de la plataforma, normas adicionales de seguridad, etc.), 
precisamente previendo su conversión futura a metro o a suburbano. El metro ligero alcanzaba una velocidad máxima similar a la del tranvía rápido (60 km/h y más), pero la velocidad de servicio era más alta (entre 30 y $40 \mathrm{~km} / \mathrm{h}$ ) por sus mejores características dinámicas (aceleración y frenado). Asimismo, estaba la diferencia de su mayor capacidad y las modificaciones adaptativas del material rodante (Pithardt, 1975). Sin embargo, hubo diversas combinaciones tecnológicas que dificultaron su diferenciación clara y la aplicación de una nítida terminología. Kym Norley, en "Light rail: the semimetro concept" ha explicado la modernización del tranvía como un metro ligero con varios grados de desarrollo. Así pues, en general, muchos estándares tranviarios fueron sustituidos en buena parte por los ferroviarios (Norley, 2010).

Tabla 1. Los requisitos técnicos para diferentes medios de transporte público

\begin{tabular}{|c|c|c|c|c|c|}
\hline Tipo de vehículo & Autobús & Trolebús & $\begin{array}{l}\text { Tranvía } \\
\text { convencional }\end{array}$ & $\begin{array}{l}\text { Tranvía } \\
\text { rápido }\end{array}$ & Metro ligero \\
\hline $\begin{array}{l}\text { Capacidad } \\
\text { asientos }\end{array}$ & $20-40$ & $25-50$ & $25-50$ & $25-80$ & $25-80$ \\
\hline $\begin{array}{l}\text { Capacidad } \\
\text { máxima }\end{array}$ & $\begin{array}{l}45-75 \\
\text { (Articulado: } \\
100-160)\end{array}$ & $\begin{array}{l}45-90 \\
\text { (Articulado: } \\
\text { 100-160) }\end{array}$ & $75-100$ & $100-400$ & $100-400$ \\
\hline $\begin{array}{l}\text { Flujo de } \\
\text { pasajeros en una } \\
\text { hora en una } \\
\text { dirección }\end{array}$ & $3.000-9.000$ & $4.000-10.000$ & $8.000-12.000$ & $12.000-25.000$ & $12.000-25.000$ \\
\hline $\begin{array}{l}\text { Velocidad } \\
\text { máxima, km/h. }\end{array}$ & 65 & 65 & $50-55$ & $60-70$ & $70-100$ \\
\hline $\begin{array}{l}\text { Velocidad } \\
\text { comercial, km/h. }\end{array}$ & $17-20$ & $16-18$ & $14-16$ & $25-35$ & $35-55$ \\
\hline $\begin{array}{l}\text { Aceleración, } \\
\mathrm{m} / \mathrm{s} 2 \text {. }\end{array}$ & $1,0-1,3$ & $1,1-1,2$ & $1,1-1,2$ & $1,2-1,4$ & $1,2-1,4$ \\
\hline Frenado, m/s2. & $1,0-1,2$ & $1,0-1,3$ & 1,2 & $1,2-1,5$ & $1,2-1,5$ \\
\hline $\begin{array}{l}\text { Distancia entre } \\
\text { paradas, } \mathrm{m} \text {. }\end{array}$ & $300-500$ & $300-500$ & $250-500$ & $300-1.500$ & $300-1.500$ \\
\hline $\begin{array}{l}\text { Separación de } \\
\text { las calles y } \\
\text { carreteras }\end{array}$ & No & No & $\begin{array}{l}\text { Principalmente } \\
\text { funcionamient } \\
\text { o mixto con } \\
\text { tráfico rodado, } \\
\text { aunque con } \\
\text { algunos } \\
\text { tramos en } \\
\text { plataforma } \\
\text { separada }\end{array}$ & $\begin{array}{l}\text { Separación con } \\
\text { plataforma } \\
\text { separada, } \\
\text { con } \\
\text { funcionamiento } \\
\text { mixto en áreas } \\
\text { centrales, } \\
\text { separación de } \\
\text { niveles en las } \\
\text { intersecciones, } \\
\text { prioridad en la } \\
\text { señalización, } \\
\text { sin posibilidad de } \\
\text { conversión en } \\
\text { metro }\end{array}$ & $\begin{array}{l}\text { Separación } \\
\text { completa, } \\
\text { en áreas densas } \\
\text { en túnel o } \\
\text { viaducto, } \\
\text { con estándares } \\
\text { similares al } \\
\text { metro }\end{array}$ \\
\hline
\end{tabular}

Fuente: Vucnic, V. R. (1972) Light Rail Transit Systems: A Definition and Evaluation, Report Department of Transportation Urban Mass Transportation Administration, p. 28; Vucnic, V. R. (2007) Urban Transit. Systems and Technology, New Jersey: John Wiley \& Sons, Inc, p. 311; Norley, K. (2010) Light rail: the semi-metro concept, 33rd Australasian Transport Research Forum (ATRF), Canberra, ACT, Australia, p. 4; Efremov, I. S. (1969) Trolleibusi, Moskva: Vysshaya Shkola, pp. 15-17; Yudin, V. A., Samoilov, D. S. (1975) Gorodskoi Transport, Moskva: Stroiizdat, pp. 23-33.

Lo cierto es que la diferencia entre tranvía rápido y metro ligero u otros términos de aquel período (pre-metro, demi-metro) no estuvo bien definida y la propia terminología de las fuentes puede inducir a error. Esa confusión se puede notar, por ejemplo, en el trabajo de Khitzenko, en cuyos proyectos

ACE, 16 (4.6) CC BY-ND 3.0 ES | UPC Barcelona, España | Los tranvías en los países del socialismo real de los años 
de tranvía rápido los tramos subterráneos fueron denominados tanto tranvía subterráneo como demi-metro o semi-metro, mientras que pre-metro o metro ligero eran términos que correspondían a "los tramos subterráneos del tranvía construidos con estándares de metro" (Khitzenko, 1976, p. 7).

El tranvía rápido fue pensado como un tranvía con plataforma única, separada de los otros medios de transporte, con material rodante más veloz y de mayor capacidad que el tranvía convencional, así como mejores características dinámicas, mayor distancia entre paradas y algunos tramos subterráneos, en principio no más del 10-15\% (Khitzenko, 1976; Zakopal, 1977). La diferenciación clave estaba en que el tranvía rápido no asumía los estándares funcionales del metro. El tranvía rápido no fue un metro ni un tren suburbano, aunque pudo compartir sus características en tramos subterráneos y pudo funcionar en áreas suburbanas. Además, presentaba varias diferencias singulares en comparación con el tranvía convencional. Primero, por la separación respecto del tráfico automovilístico mediante plataforma reservada. Segundo, por la mejora del material rodante, con una velocidad máxima hasta de $65 \mathrm{~km} / \mathrm{h}$, una velocidad comercial hasta de 18-20 km/h en la ciudad consolidada y de $30-35 \mathrm{~km} / \mathrm{h}$ en la periferia urbana, una mejora notable de las características de aceleración y frenado, una mayor capacidad mediante el desarrollo de composiciones articuladas, una altura ajustada a la plataforma de las paradas y una conducción menos ruidosa. (Tabla 1).

Para la implementación del tranvía rápido se necesitaba el desarrollo de nuevos modelos de material rodante. En la URSS se usaron principalmente el modelo KTM-5M3 de 4 ejes (Fig. 2), producido por la compañía UKVZ (Ust-Katav) desde 1969, el modelo RVZ-6M2 de 4 ejes (Fig. 3), producido por Rizhskii Vagonostroitel'nii Zavod desde 1974 (Yudin, Samoilov, 1975) así como los modelos T2 y T3 de la empresa checa ČKD Tatra, que permitían el sistema de unidades múltiples, lo que mejoraba su capacidad (Ivanov, Ponomarev, leropolskii, 1977). En la RSC se utilizaban los modelos T2, T3 y K2 (modelo articulado de 6 ejes) de ČKD Tatra para los proyectos de tranvía rápido (Fig. 4, 5 y 6). Solo a partir de mediados de los años 80 se introdujo el nuevo modelo articulado KT8D5 de 8 ejes que respondía mejor a las características planteadas para el tranvía rápido.

Figura 2. KTM-5M3 producido en la URSS desde 1973

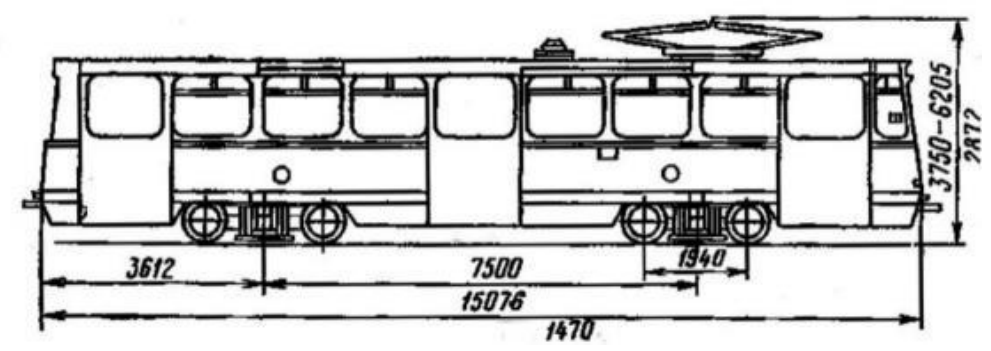

Fuente: Ponomarev, A. A. (1975) Tramvainie vagoni RVZ-6M2 i KTM-5M3, Moskva: Transport, 5.

Figura 3. RVZ-6M2 producido en la URSS desde 1975

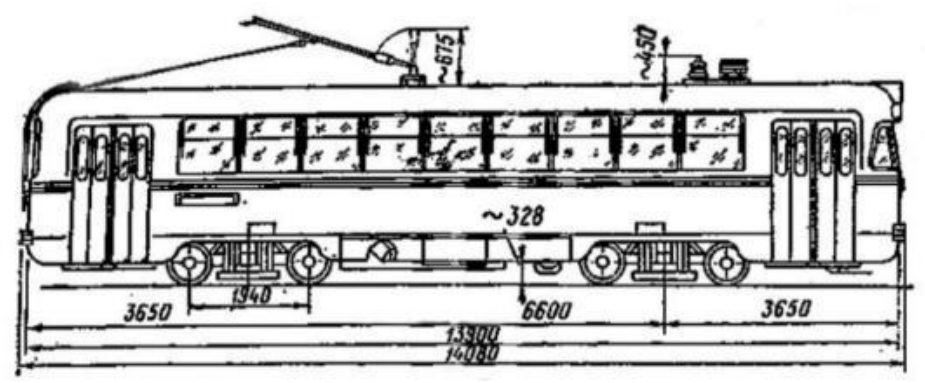

Fuente: Ponomarev, A. A. (1975) Tramvainie vagoni RVZ-6M2 i KTM-5M3, Moskva: Transport, 4.

ACE, 16 (4.6) CC BY-ND 3.0 ES | UPC Barcelona, España | Los tranvías en los países del socialismo real de los años 


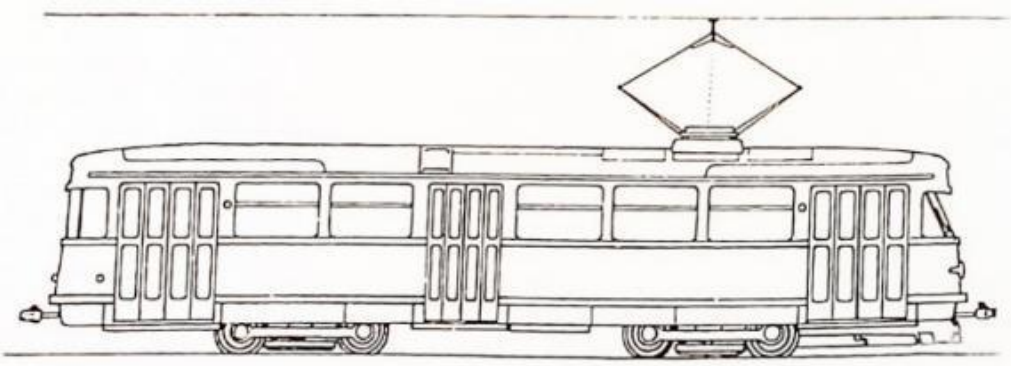

Fuente: Bauer, G. (1975) Straßenbahnen in der Tschechischen und Slowakischen Republik von der Pferdebahn zum Tatrawagen, Praha: NADATUR, 12.

Figura 5. Tatra T3SU para la URSS producido desde 1963

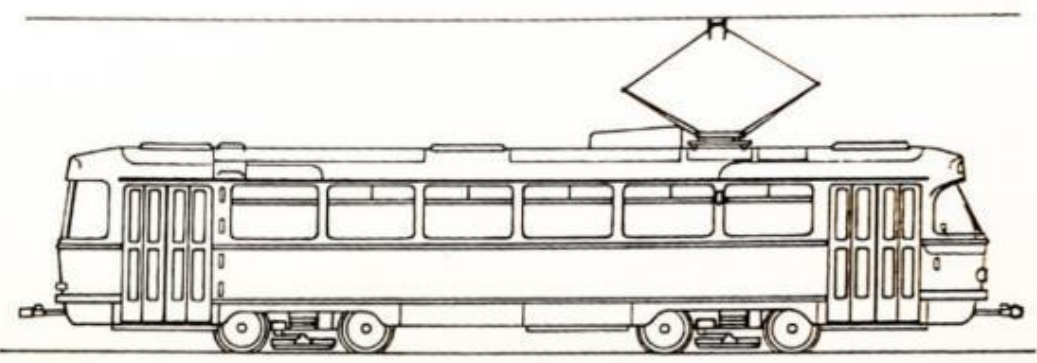

Fuente: Bauer, G. (1975) Straßenbahnen in der Tschechischen und Slowakischen Republik von der Pferdebahn zum Tatrawagen, Praha: NADATUR, 13.

Figura 6. Tatra K2 para RSC producido desde 1966

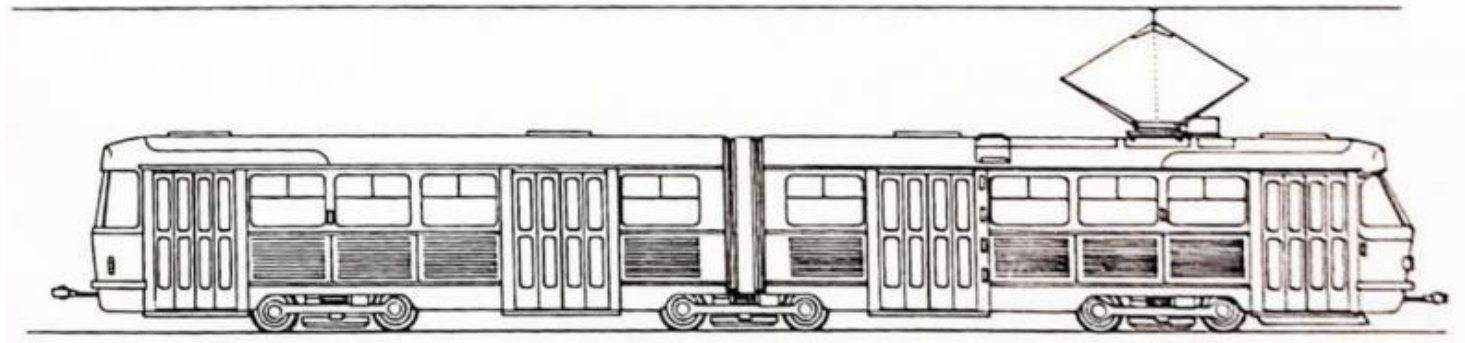

Fuente: Bauer, G. (1975) Straßenbahnen in der Tschechischen und Slowakischen Republik von der Pferdebahn zum Tatrawagen, Praha: NADATUR, 13.

En la URSS de los años sesenta y setenta, el tranvía rápido se aplicó sobre todo en las ciudades grandes, como Leningrado, Kiev, Gorki, Omsk, Saratov, etc. Las ciudades medianas, por su parte, siguieron servidas principalmente con tranvías convencionales y trolebuses, como Oryol, Tula, Ryazan, Toliatti, etc., si bien el tranvía rápido fue implantado en otras más grandes, como por ejemplo Ust-Ilimsk, Lviv, Izhevsk, Stari Oskol Yaroslavl, etc.

En la RSC, sin embargo, el tranvía rápido fue implementado en las ciudades medianas como, por ejemplo, en Ostrava, Brno y Košice, así como en Bratislava como solución temporal y en Praga como sistema complementario al metro. Habiendo menor necesidad objetiva de tranvía rápido, hubo mejor disposición para su uso, debiéndose tener en cuenta que ČKD Tatra era la casa fabricante más adelantada de los países comunistas.

ACE, 16 (4.6) CC BY-ND 3.0 ES | UPC Barcelona, España | Los tranvías en los países del socialismo real de los años 


\section{Dos casos diferenciales de estudio: Ostrava y Yaroslavl}

La ciudad checa de Ostrava y la ciudad rusa de Yaroslavl presentaron dinámicas bien distintas en el desarrollo de su sistema tranviario a lo largo de los años cincuenta, sesenta y setenta. Las hemos elegido precisamente por representar dos escenarios disímiles en términos históricos y por disponer de decisiones urbanas y de transporte que pueden ser analizadas en términos comparativos.

Ostrava es un caso en el que el tranvía fue reconocido muy pronto como el medio de transporte más adecuado para el acceso a las áreas industriales y para superar el aislamiento relativo de algunas zonas urbanas. Ello supuso que el sistema de tranvía fuera mantenido y mejorado ya desde los años cincuenta. En los años setenta, con el desarrollo suburbano, se potenció su papel con soluciones de modernización orientadas al tranvía rápido.

El caso de Yaroslavl representa una situación completamente distinta: a pesar de ser una ciudad con un desarrollo urbano y demográfico significativo, el tranvía perdió su papel anterior desde finales de los años cincuenta y fue en buena parte sustituido por trolebuses y autobuses a lo largo de los años sesenta. Sin embargo, en los años setenta su modernización cobró cierta importancia, aunque solo para las conexiones consideradas más urgentes.

Estas diferencias se deben a diferentes factores. Destacamos, por un lado, la diversidad de políticas de elección de medios de transporte público colectivo, en relación con el tamaño de la ciudad, sus condiciones espaciales y su capacidad económico-financiera. Por otro lado, la diferente congruencia e interrelación de los planes urbanos y de transporte, especialmente, en la organización del trabajo entre institutos y planificadores, así como en planteamientos y calidad de implementación de los planes generales de transporte.

\subsection{Ostrava: el tranvía rápido como elemento clave para el tráfico suburbano y el desarrollo metropolitano}

Ostrava es una ciudad industrial situada en el noreste de la RCS, en la región de Moravia-Silesia en el lugar de confluencia de los ríos Ostravice, Odra y Opava. En 1970 la ciudad tenía 297.000 habitantes en su término y alrededor de 1 millón en su área metropolitana. Durante el siglo XIX la ciudad era ya un centro importante de la producción minera y siderúrgica, lo que influyó en la formación de una estructura urbana fragmentada. El tranvía tuvo un papel importante en la accesibilidad de las áreas industriales. Con el establecimiento del régimen comunista, la ciudad continuó el desarrollo de la industria pesada, convirtiéndose en un centro industrial importante para el desarrollo económico del país. El período de reconstrucción y de desarrollo urbano fue un proceso simultáneo después de la Segunda Guerra Mundial. Hubo un desarrollo intensivo de actividades industriales y un problema continuado de falta de vivienda (Zarecor, 2013). En la difícil relación industria-residencia, con las áreas concentradas y especializadas funcionalmente se detectó enseguida la necesidad de proveer conexiones eficaces. Ello se realizó con los nuevos modelos de tranvía T1 (desde 1952) y T2 (desde 1958) que permitieron crear trenes y aumentar la capacidad de pasajeros (hasta 150-200 pasajeros).

La ciudad de Ostrava representa el caso de uso general del tranvía: mantuvo la red tranviaria en la ciudad consolidada, la modernizó y la amplió para el crecimiento periférico. Así, en los años cincuenta el desarrollo de la nueva área residencial de Poruba fue acompañado con la correspondiente extensión de la red tranviaria. Algo similar ocurrió con el desarrollo residencial de Hrabuvka en el sur de la ciudad, que se fundó en las prolongaciones de las líneas tranviarias existentes. Así, en el período de posguerra, el desarrollo intensivo de la industria fue acompañado de una construcción masiva de viviendas y de la mejora del transporte público. El carácter concentrado pero fragmentado de las

ACE, 16 (4.6) CC BY-ND 3.0 ES | UPC Barcelona, España | Los tranvías en los países del socialismo real de los años 
áreas urbanas contribuía al incremento del tráfico de pasajeros, de manera que el tranvía tuvo una gran utilidad para superar sus distancias. Las áreas industriales de Vítkovice y Nová hut' fueron los focos principales de las decisiones de la localización de las nuevas áreas residenciales en los años sesenta. Los principales desarrollos urbanos se realizaron con los distritos residenciales de Zábřeh, Výškovice, Dubina y Bělský Les. Su comunicación insatisfactoria con el centro de la ciudad requería la planificación de la red tranviaria (Zmija, 1985), aunque las conexiones potentes de transporte público se orientaron sobre todo a mejorar las relaciones entre las áreas industriales y las residenciales, y no tanto con el centro de la ciudad (Zarecor, 2013).

Las necesidades de crecimiento urbano intensificaron la necesidad de elaboración de un Plan general de transporte urbano (Dopravní Generel), lo que ocurrió relativamente temprano, entre los años 1960 y 1964. Este plan se basó en los resultados de un estudio complejo y extenso del transporte urbano de Ostrava, realizado por el Instituto Estatal de planificación del transporte con sede en Brno (Státní Ústav pro Projektovaní Dopravních Staveb v Brně), que propuso una extensión significativa de las redes tranviarias hasta el año 1970. De cara al desarrollo urbano futuro de la ciudad, las comparaciones técnicas entre los medios de transporte público colectivo dieron como resultado que el autobús y el trolebús, por compartir la infraestructura viaria con el transporte privado, no resultaban estables ni atractivos en el caso de un esperado crecimiento del tráfico automovilístico.

Entonces no se negaba el crecimiento del tráfico de transporte privado, como ocurría en la URSS, sino que se suponía que su crecimiento futuro debería resultar en un "enfrentamiento de intereses" de transporte viario privado y público (Zmija, 1967). Este planteamiento contrastaba especialmente con muchos de los expuestos en aquel período en otros países del socialismo real, cuando se cuestionaba la presencia del tranvía, no solo en las áreas centrales sino también en las periféricas.

La propuesta de tranvía rápido fue expresada formalmente en el Plan general urbano (Uzemní Plan Města) de 1965. En él se indicaba que la ampliación del sistema debía resolverse de acuerdo con los parámetros técnicos del tranvía rápido: plataforma separada, mayor distancia entre paradas y alturas de plataformas ajustadas con la altura de suelo de los vehículos (Archivo Municipal de Ostrava, 1965). Así pues, si en los años cincuenta el tranvía había sido mantenido y mejorado (algo diferencial en Ostrava respecto de otras ciudades del Centro y Este de Europa), en los sesenta sus líneas no solo debían ampliarse sino también modernizarse con la previsión futura de conversión al sistema de tranvía rápido.

Aunque Ostrava era una ciudad mediana o mediana-grande, la decisión de incorporar a su término las áreas suburbanas supuso pasar de unos 300.000 habitantes a unos 700.000, extendiendo su territorio hasta 25.000 ha (Archivo Municipal de Ostrava, 1977) y convirtiendo la ciudad en una aglomeración industrial (Barton, 1975). Este tipo de solución fue un fenómeno generalizado y sucedió en muchas grandes ciudades europeas desde mediados de los años sesenta, lo que en Ostrava, que en los años setenta continuó con el desarrollo industrial y la zonificación de sus áreas urbanas, incrementó mucho el tráfico en la aglomeración.

El Plan General de Transporte de 1973 estableció la red tranviaria y apuntó la necesidad futura de estudios y la introducción del tranvía rápido. Sin embargo, no consideró el desarrollo del transporte público en la escala de la ciudad-región. Cabe destacar que el Plan de zonificación (Směrný územní plan, SúP) de 1977 (Fig. 7) no planificó las nuevas áreas residenciales en el territorio urbano, más bien continuó con la extensión de Jižní město en el sur de la ciudad y de las áreas industriales. Por ello, no hubo una extensión significativa de las líneas tranviarias (la longitud debió crecer de 48,6 km en 1977 a 57,7 km en los años 2000), pero sí un desarrollo cualitativo, orientado a la modernización del material rodante y a la segregación de plataformas.

ACE, 16 (4.6) CC BY-ND 3.0 ES | UPC Barcelona, España | Los tranvías en los países del socialismo real de los años 


\section{ACE Architecture, City and Environment}

E-ISSN 1886-4805

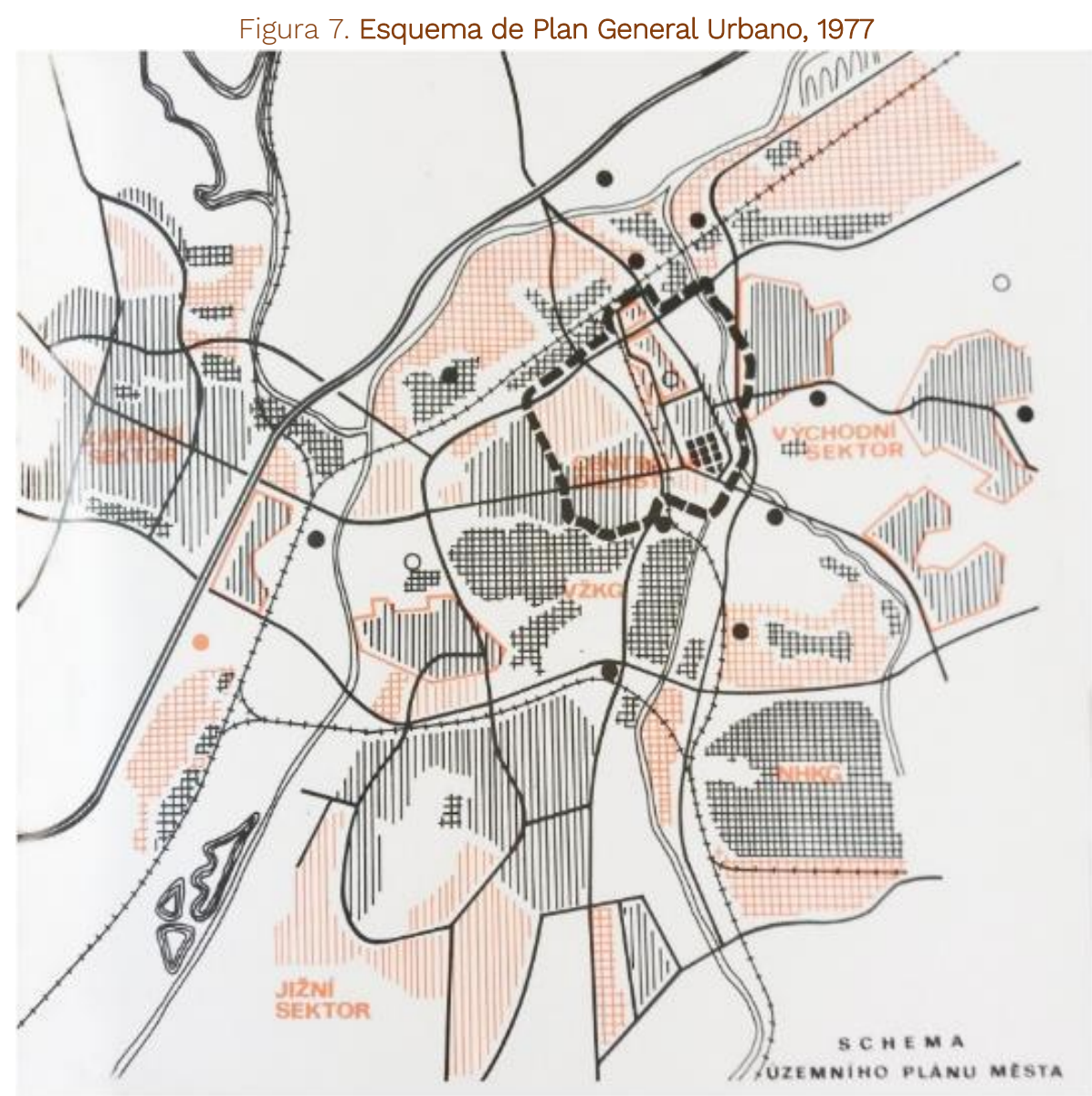

IIIIIII Área urbana construida

[ililill Nuevas áreas urbanas (residenciales y equipamientos)

IIIIIII Áreas residenciales existentes de baja densidad

Áreas industriales existentes

Nuevas áreas industriales

[-.] El centro urbano

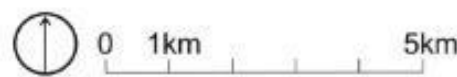

Nota: Se puede apreciar un desarrollo residencial limitado en el sur y las extensiones de áreas industriales de la ciudad. Fuente: Archivo Municipal de Ostrava (1979)

Fueron varias las decisiones que iniciaron el desarrollo del tranvía rápido y la necesidad de reconsideración del recién aprobado Plan Teneral de Transporte de 1973 (Fig. 8). Primero, el estudio prospectivo de la aglomeración de Ostrava (Prognostická studie vybavení ostravsko-karvinské aglomerace) realizado por VúVA, el Instituto de investigación de la construcción y la arquitectura (Vědeckotechnická společnost, Výzkumný ústav výstavby a architektury) de Brno en 1972, que dio impulso para el anuncio en la XV Reunión del Partido Comunista en 1976 (XV sjezdu Komunistické Strany Československa, 1977) acerca de la necesidad de la "mejora, modernización y prioridad del transporte público rápido en las grandes ciudades y aglomeraciones urbanas” (O Zkvalitňování, modernizaci a preferenci hromadné dopravy ve velkých městech a městských aglomeracích) (Archivo Municipal de Ostrava, UDIMO, 1978c). Segundo, el documento "Perspectivas de desarrollo a largo plazo del transporte en la República Socialista Checa hasta 1990" (Dlouhodobý Výhled Rozvoje Dopravy v ČSR do roku 1990) publicado en 1974 por el Ministerio del Interior (Ministerstvo Vnútra ČSR). En ambos textos, el transporte ferroviario resultaba prioritario, especialmente el tranvía rápido.

ACE, 16 (4.6) CC BY-ND 3.0 ES | UPC Barcelona, España | Los tranvías en los países del socialismo real de los años 
Figura 8. Plan general de transporte de Ostrava, editado en 1973 por el Departamento de transporte de la ciudad

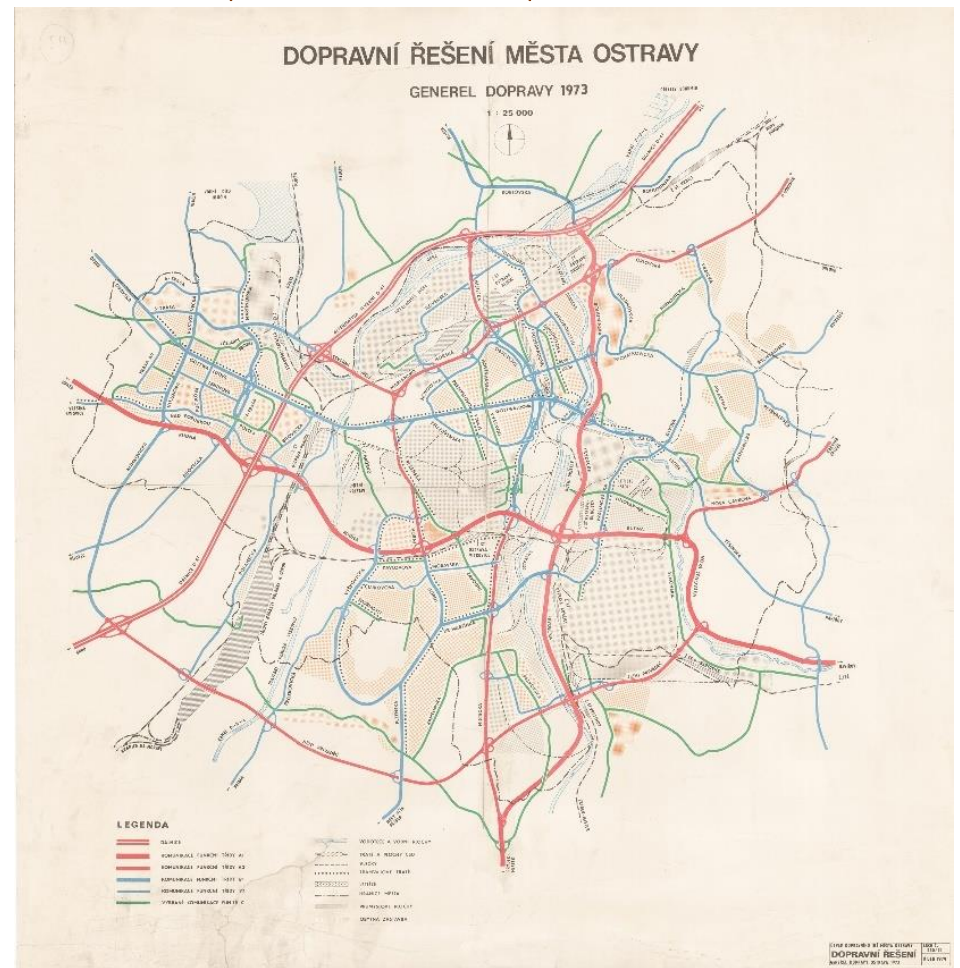

Nota: Las líneas negras punteadas corresponden al tranvía, las líneas rojas a las carreteras principales, las azules a las carreteras urbanas y las verdes a los viales conectores especiales. Fuente: Archivo Municipal de Ostrava (1973)

En relación con estas nuevas realidades, el Plan General de Transporte de 1973 había perdido relevancia, además de precisarse la ampliación del ámbito de planificación del transporte. Ello se resolvió con el "Estudio de revisión del concepto de transporte público colectivo" (Studie Přehodnocení Koncepce MHD v Ostravě), que fue ordenado por el Departamento de Transporte de Ostrava (Dopravního Inženýrství Města Ostravy) y realizado en 1974 por los Servicios estatales de ingeniería de Brno (Inženýrské Služby Český Svaz Stavebních Inženýrư v Brně). En este estudio se propuso el tranvía subterráneo para el centro de la ciudad, mientras que las áreas residenciales periféricas seguían sus líneas de tranvía convencional, de modo similar a la propuesta del Plan de transporte de 1964. Esa revisión fue basada en el Plan de Definición de la Aglomeración de Ostrava (Vymezení Aglomeraci) realizado en 1976 por el Departamento de Transporte de la ciudad.

El Gobierno de la CSR aprobó los principios de la modernización del sistema de transporte público colectivo en 1975, lo que se plasmó posteriormente en el Plan Urbano (Archivo Municipal de Ostrava, 1978c, 5). Este incorporó el proyecto de tranvía rápido de 1977 (Archivo Municipal de Ostrava, 1978b, 6), argumentando solventemente su papel primordial para un desarrollo racional de la aglomeración urbana (Archivo Municipal de Ostrava, 1976).

El Departamento de ingeniería de tráfico de la ciudad de Ostrava (Útvar Dopravního Inženýrství Města Ostravy, -UDIMO-) hizo en 1978 varios seminarios técnicos: "Extensión del sistema de tranvía rápido a las áreas suburbanas de la ciudad de Ostrava" (Rozšírení systému RT do príměstských oblastí města Ostravy) y "Solución compleja de transporte en la aglomeración de Ostrava" (Komplexní řešení dopravy $v$ ostravské aglomeraci). Fueron allí destacados dos problemas en el transporte público a largo plazo que hicieron pensar en la necesidad de introducción del tranvía rápido en Ostrava.

ACE, 16 (4.6) CC BY-ND 3.0 ES | UPC Barcelona, España | Los tranvías en los países del socialismo real de los años 13 1960: de la crisis al impulso. DOI: http://dx.doi.org/10.5821/ace.16.46.9260 
El primero, el crecimiento de los tiempos de viaje con la expansión del territorio urbano en 14-17 km hacia las áreas suburbanas, como las de Hlučín, Bohumín, Haviřov y Frýdek Místek, donde se estudió la conexión con tranvía rápido, ya que las líneas de ferrocarril se planificaron sin considerar las necesidades de comunicación de las áreas suburbanas. El segundo, cierta congestión del tráfico de transporte público por compartir la calzada con el resto del transporte rodado y, como resultado, una velocidad de servicio baja de 15 a $20 \mathrm{~km} / \mathrm{h}$, poniendo por ello el objetivo de incrementar la velocidad hasta $35 \mathrm{~km} / \mathrm{h}$ (Archivo Municipal de Ostrava, 1978d).

Entre otros documentos importantes, merece mención también el "Informe explicativo sobre la preparación e implementación del sistema de tranvía rápido en las ciudades de Brno y Ostrava” (Důvodová Zpráva o zajištění připravy a realizaci systému rychlé tramvaje v městech Brně a Ostravě), editado por el Gobierno checoslovaco en 1978. En la propuesta para Ostrava se desarrollaban tres líneas de tranvía rápido en las áreas urbanas: 1) Jižní město - Vítkovice - centrum; 2) Jižní město Severní průmyslové zóny - centrum; 3) Poruba - centrum - Nová hut' Klementa Gottvalda (Archivo Municipal de Ostrava, 1978a, 14) (Fig. 9 y 10). La ampliación venía facilitada por la preexistencia de infraestructura tranviaria. Sin embargo, a pesar de que la accesibilidad de las áreas suburbanas era la razón de ser del tranvía rápido, en las primeras fases de desarrollo, salvo en el área residencial de Havírov, se preocuparon más por la modernización del sistema tranviario existente en el centro.

Figura 9. Las fases de construcción del tranvía rápido en Ostrava 1978-2000
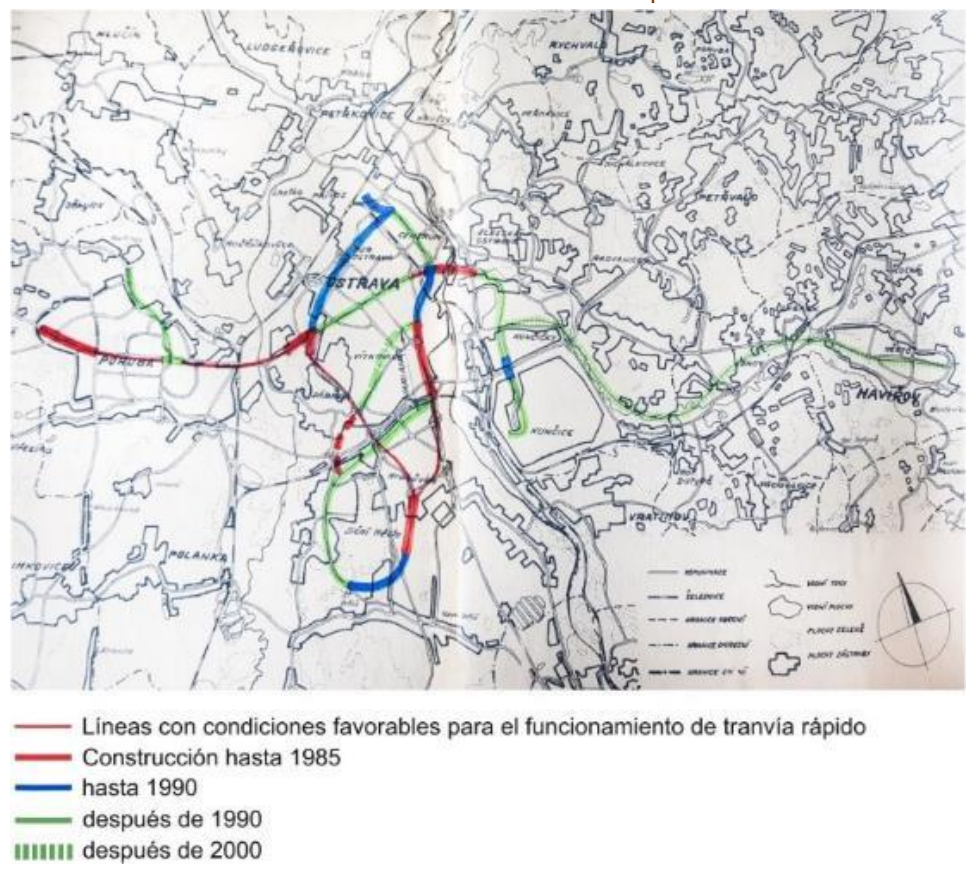

Nota: El esquema de la implementación gradual del sistema de tranvía rápido con la primera conexión con área suburbana Havírov. Fuente: Archivo Municipal de Ostrava (1978c).

El tranvía rápido se definió como el medio principal de transporte público urbano, con los autobuses y trolebuses como medios complementarios, lo que supuso la reorganización de todo el sistema de transporte público colectivo de la aglomeración. La red de autobuses debía reducirse, mientras que el transporte público eléctrico debía potenciarse, para conseguir un alto porcentaje del movimiento de pasajeros (Novák, 1982) (Fig. 11 y 12). Pronto se dieron cuenta de que no era posible mejorar radicalmente la situación con la introducción de algunas líneas de tranvía rápido, sino que debían mejorar todo el conjunto del sistema de transporte público colectivo (Archivo Municipal de Ostrava, 1978c).

ACE, 16 (4.6) CC BY-ND 3.0 ES | UPC Barcelona, España | Los tranvías en los países del socialismo real de los años 14 1960: de la crisis al impulso. DOI: http://dx.doi.org/10.5821/ace.16.46.9260 
Figura 10. Esquema de la aglomeración urbana de Ostrava y el desarrollo del sistema de tranvía rápido a finales de los años setenta

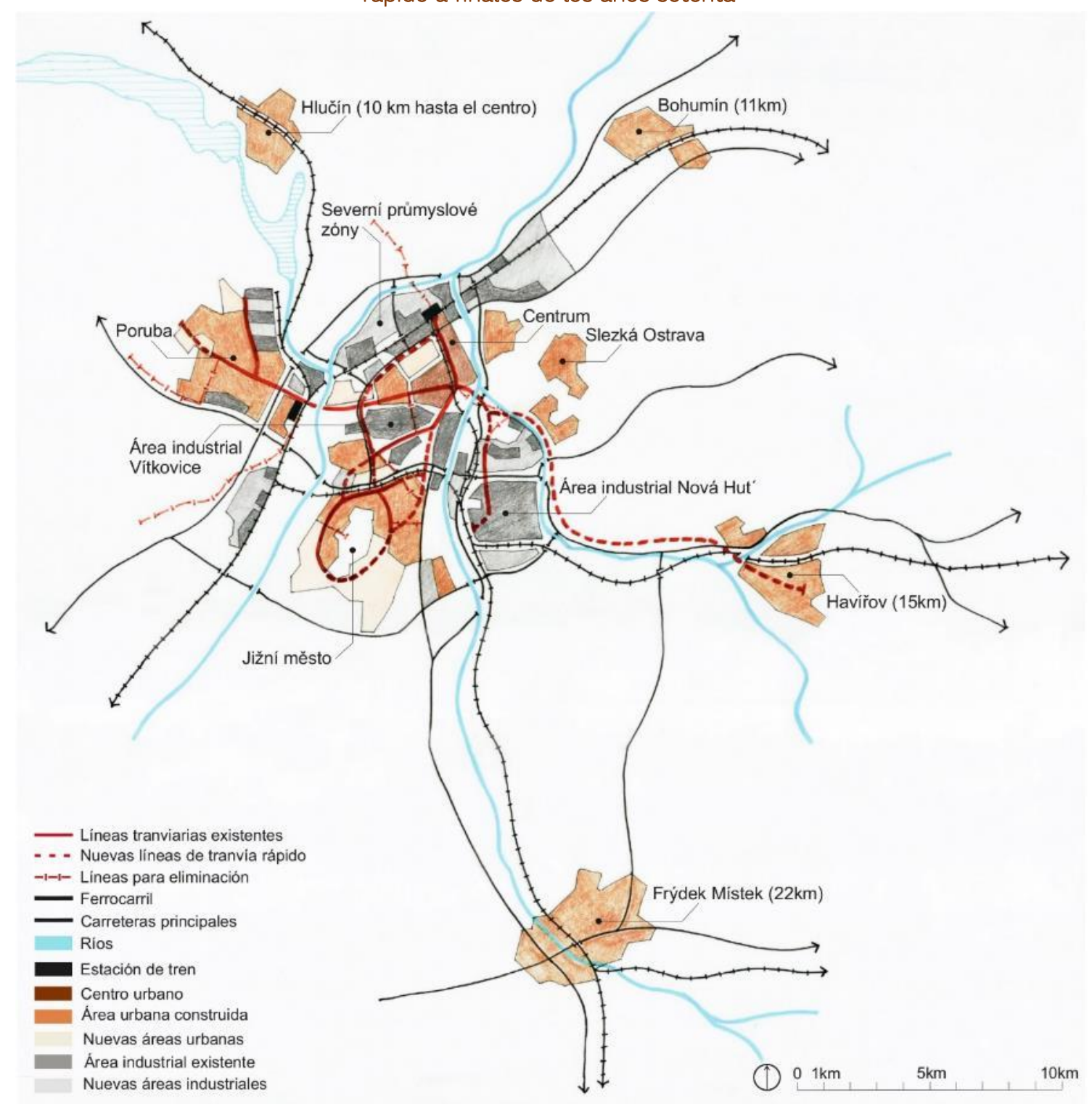

Nota: Apréciese la modernización del sistema existente y su adaptación al tranvía rápido, en especial la primera conexión con el área suburbana de Haviŕrov. Fuente: Elaboración propia a partir del Plan General Urbano de 1977, el Plan de Tranvía rápido de 1978, el plano de la red existente de tranvía de 1976 y el plano de la aglomeración urbana de 1976.

Frente al tren suburbano, el tranvía rápido fue considerado como una solución suficiente (Archivo Municipal de Ostrava, 1974a). En 1977 el Consejo del comité nacional de la ciudad de Ostrava aprobó la conversión del sistema existente en tranvía rápido basándose en el "Estudio del desarrollo de un sistema de tranvía rápido" (Studie rozvoje systému rychlé tramvaje, 1977) (Archivo Municipal de Ostrava, 1977). El objetivo principal era la creación de un sistema integrado de transporte público en la aglomeración urbana de Ostrava a largo plazo (Archivo Municipal de Ostrava, 1976).

ACE, 16 (4.6) CC BY-ND 3.0 ES | UPC Barcelona, España | Los tranvías en los países del socialismo real de los años 


\section{ACE Architecture, City and Environment}

E-ISSN 1886-4805

Figuras 11 y 12. Imágenes del tranvía rápido en Ostrava a finales de los años setenta

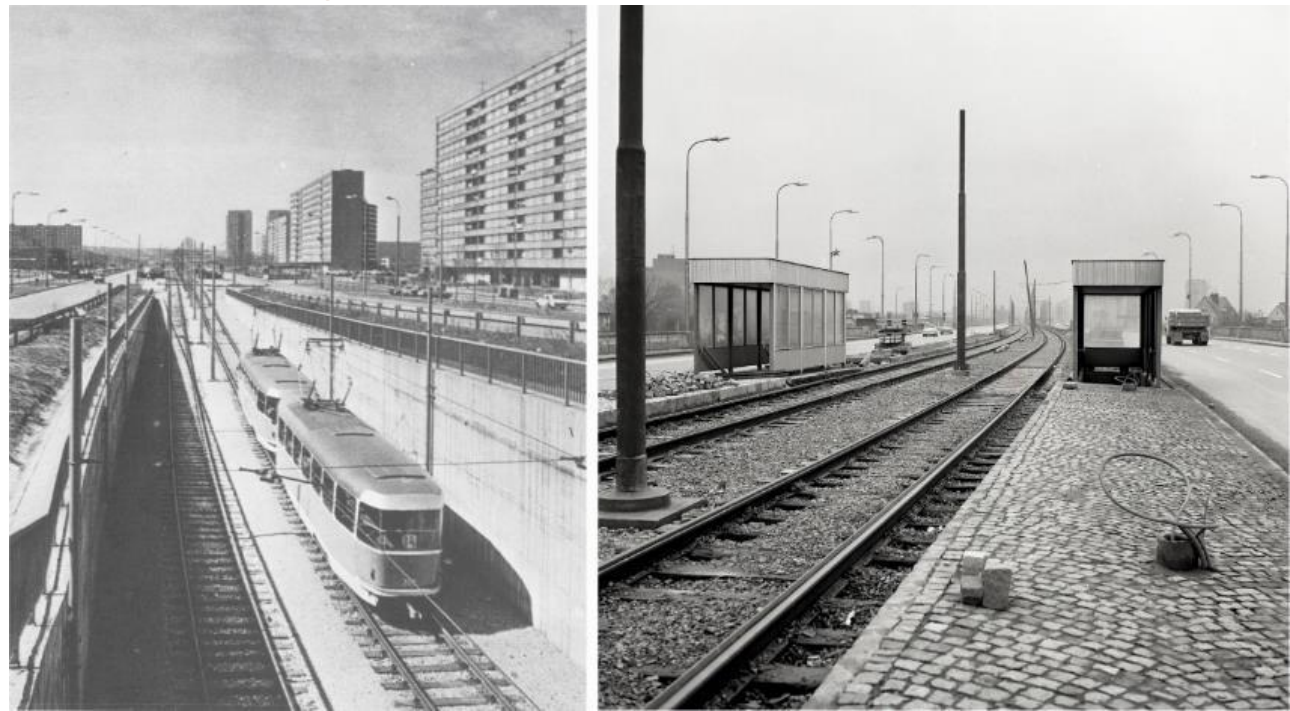

Nota: A la izquierda, una de las pocas soluciones de tranvía subterráneo implementada en Ostrava, en el área Tř́la Dr. Martínka Ostrava-Hrabůvka a finales de los años setenta. Este tipo de soluciones respondía principalmente a las intersecciones con las carreteras de nivel regional. Nota: A la derecha, reconstrucción en 1978 de la parada Dolní, en la ciudad consolidada (calle Plzénská). La implementación de pasos peatonales subterráneos para cruzar la calzada de algunas avenidas o carreteras en lugares de tráfico intenso y alcanzar así los andenes del tranvía que circulaba segregado por el centro de la vía fue unas de las soluciones más ampliamente aplicadas en Checoslovaquia durante los años sesenta y setenta. Fuentes: Utvař dopravního inženýrství města Ostravy (1982). Doprava a Životní Prostředí v Ostravé, Ostrava, UDIMO, 10; www.transphoto.com.

Se fue construyendo el tranvía rápido, en plataforma reservada superficial en un $80 \%$ de la traza y con algunos tramos subterráneos (20\%) en las intersecciones con las carreteras. La longitud total de las líneas creció hasta $48 \mathrm{~km}$. La capacidad de transporte para el tranvía rápido se planeaba incrementar hasta 12.000-18.000 pasajeros por hora en una dirección. El tranvía rápido constituyó alrededor del 75\% del sistema tranviario (Zakopal, 1977) y proveyó el máximo tiempo de acceso de la aglomeración urbana hasta 45 min (Archivo Municipal de Ostrava, UDIMO, 1976). Se previó, además, la sustitución del modelo Tatra T-3 por el T-5 en un horizonte de quince años (Archivo Municipal de Ostrava, 1974a). Aparte de ello, se planteó una política de regulación del transporte motorizado mediante un reparto modal con una proporción mayor del transporte público eléctrico (Archivo Municipal de Ostrava, 1974b).

Cabe destacar también la ampliación de los criterios de evaluación del tranvía rápido con nuevos factores a considerar, medioambientales y sociales, probablemente debido al trabajo conjunto de especialistas de transporte, urbanistas y sociólogos (Archivo Municipal de Ostrava, 1974b). Por ejemplo, se consideró su contribución a la mejora de la vida social mediante la extensión de la red a toda la aglomeración urbana, así como su contribución en la mejora del tráfico en las áreas urbanas concentradas (Archivo Municipal de Ostrava, 1978a) (Fig. 13). Se estudiaron también la mejora del confort en el transporte público y las relaciones entre las áreas urbanas (Archivo Municipal de Ostrava, 1974b), así como los factores de calidad ambiental (calidad del aire y ruido), a modo de continuación de los debates de los planificadores de la RSC desarrollados desde finales de los años sesenta. Por otro lado, la separación física del tranvía de los otros medios de transporte, una de las formas de lograr mayores velocidades, fue una respuesta al esperado tráfico motorizado, creciente, lo que se entendió entonces como una mejora social y ambiental. Sin embargo, la potenciación tranviaria fue más lenta de lo previsto. Se necesitó la inclusión de nuevos métodos de planificación en los planes urbanos, que se realizó solo a partir de los años ochenta (Archivo Municipal de Ostrava, 1974b). 
Figura 13. Implementación del tranvía rápido en las áreas residenciales Hrabůvka y Bělský Les

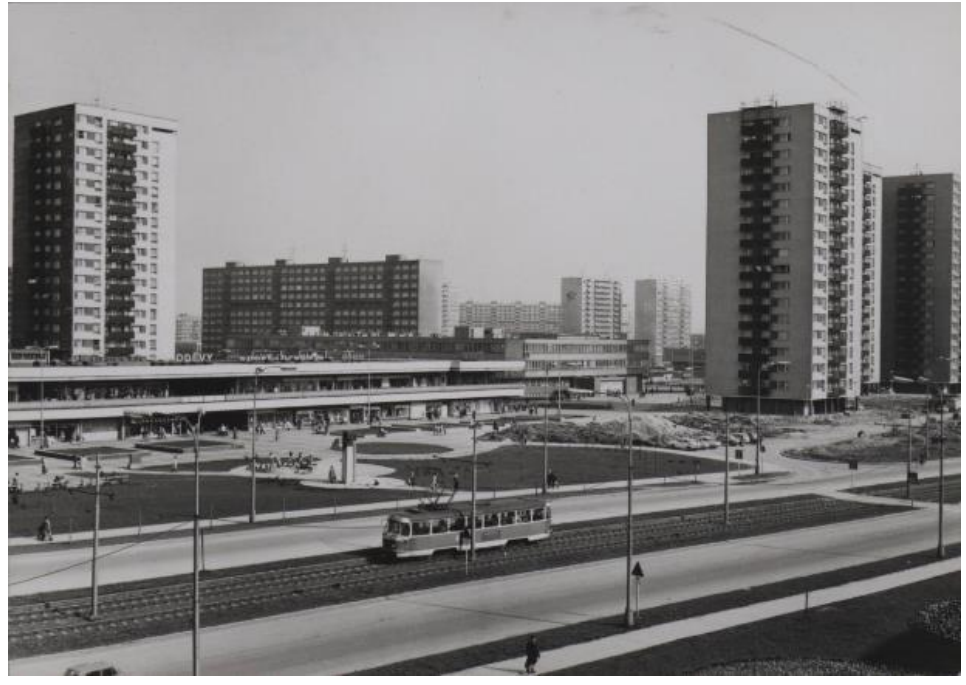

Nota: vista de la Calle Horní a finales de los años 1970.

Fuente: www.transphoto.com

En conclusión, el tranvía rápido de Ostrava fue una solución realizada con las posibilidades técnicoeconómicas existentes y basada en la idea de segregación de plataforma, en la mejora de las características técnicas del material rodante y en el perfeccionamiento de la organización y gestión de los viajes, todo ello sin implicar grandes intervenciones, como la organización de tramos subterráneos y separación de niveles en intersecciones. Por otro lado, se prestó atención al asunto de la planificación conjunta del crecimiento urbano y de la movilidad. Una sucesión de estudios de transporte con alternativas y la relación articulada entre órganos estatales y locales contribuyeron a una solución bien desarrollada para todo el sistema de transporte público colectivo en la ciudad y su área metropolitana.

\subsection{El tranvía rápido en Yaroslavl como una solución inevitable y limitada para el crecimiento urbano}

Yaroslavl es una ciudad mediana que se sitúa a $270 \mathrm{~km}$ al noreste de Moscú, junto al río Volga. A finales de los años sesenta, la ciudad tenía alrededor de 500.000 habitantes. Fue también un centro industrial importante del país, con refinería de hidrocarburos e industria química, así como con fábricas de motores, de neumáticos y de materiales de construcción. La potencia y variedad industrial fue apoyada con la apertura de varios centros de investigación y universidades en los años cincuenta y sesenta. La ciudad no fue bombardeada durante la Segunda Guerra Mundial lo que facilitó la realización de las propuestas de extensión y renovación urbana en los años cincuenta, en vez de la habitual reconstrucción.

El tranvía se mantuvo durante el periodo de posguerra, dando prioridad a la extensión de las líneas de autobuses y a la introducción del servicio de trolebuses. La extensión se planificaba en la dirección sur y suroeste (Saprykina, 2006), mientras que la renovación se basaba en lo que se denominaba agrandamiento de las manzanas y perfeccionamiento de las calles, manteniendo su estructura urbana compacta y radial concéntrica. En el inicio de la posguerra, se mantuvo también la red de tranvía por no tener otros medios alternativos. Unos de los problemas del anhelado desarrollo de los trolebuses y los autobuses en los años cincuenta fue la carencia de infraestructura viaria en condiciones suficientes. Desde finales de los años cincuenta y en los años sesenta, sin embargo, se procedió a la eliminación de buena parte de la infraestructura tranviaria en la ciudad, apoyada en la construcción de calzadas y la extensión paulatina del funcionamiento de buses y trolebuses.

ACE, 16 (4.6) CC BY-ND 3.0 ES | UPC Barcelona, España | Los tranvías en los países del socialismo real de los años 17 1960: de la crisis al impulso. DOI: http://dx.doi.org/10.5821/ace.16.46.9260 
El Plan General Urbano (Generalnii Plan Goroda) de 1960 fue pensado para 550.000 habitantes. Sin embargo, en 1961 el Comité Estatal para la Construcción de la República Socialista Federativa Soviética de Rusia (Gosstroi RSFSR) hizo una propuesta para la redacción del nuevo plan urbano por la necesidad de aumentar la población hasta 650.000 habitantes, cuya redacción concluyó en 1963 (Archivo Estatal de Economía de Rusia, -GAE-, 1963-1988). La aprobación del Plan General Urbano por todos los ministerios y departamentos involucrados fue realizada cinco años después, en 1968 (GAE, 1963-1988). Sin embargo, todos estos documentos urbanísticos carecieron de esquemas o estudios de transporte urbano (Archivo Estatal de la región de Yaroslavl, 1969).

Desde mediados de los años sesenta, el crecimiento urbano llegó a un nivel crítico con la proyección y construcción de nuevas áreas residenciales, como las de Bragino (140.000 habitantes), Zavolzhskii (170.000 habitantes) más el área renovada de Privolzhskii (70.000 habitantes). Se abandonó radicalmente la política de contención de población y se empezó a pensar en un nuevo plan urbano que previera la extensión significativa de las áreas periféricas. Con ello, apareció la primera propuesta de implantación del tranvía rápido.

Con la tardanza en el desarrollo del Plan de Transporte Urbano, las autoridades locales encontraron la ocasión de intervenir con unas soluciones basadas en la eliminación, sustitución o desplazamiento las líneas tranviarias. A principios de los años sesenta se debatió sobre la erradicación del tranvía del centro de la ciudad y, como resultado, entre los años 1964 y 1969, el Ayuntamiento procedió a su eliminación de las calles principales (Fig. 14). Este tipo de soluciones fue frecuente en las ciudades medianas de la URSS, pero también hubo ejemplos de eliminación parcial de líneas tranviarias en Europa del Este, sobre todo en las ciudades bombardeadas de la RDA, como Dresde o Leipzig. De este modo, los proyectos de extensión de la red tranviaria se abandonaron (Kovalev, 2005) y se produjo una reducción de la red desde los 18,3 km de 1967 hasta los 13,3 km de 1969 (Archivo Estatal de la región de Yaroslavl, 1972). Aun teniendo la necesidad concluyente de conectar las áreas residenciales del norte de la ciudad con las áreas industriales, el proyecto del tranvía no se realizó, a pesar de que la capacidad de transporte de los autobuses y los trolebuses no era suficiente (Kovalev, 2005).

De modo contradictorio, este desarrollo industrial intensivo y la consiguiente necesidad de transporte público, los tranvías fueron sustituidos por trolebuses y autobuses en las direcciones más intensas de la periferia urbana. Como resultado de estas intervenciones, desde mediados de los años sesenta Yaroslavl tuvo un sistema de trolebuses bien desarrollado que funcionó en el centro, las calles principales y todas las áreas industriales. Por su parte, el tranvía conectó algunas áreas residenciales con los bordes del centro y de las áreas industriales. Los posteriores proyectos de tranvía para mejorar la conexión entre las áreas urbanas, aunque fueron previstos en los esquemas de transporte de la compañía de transporte público de la ciudad, no se realizaron en los años sesenta.

Esta resistencia a admitir la funcionalidad del tranvía siguió en los años setenta. El Plan General Urbano realizado en 1971 por el Instituto Lengiprogor (Leningradskii Gosudarstvennii Institut Proektirovaniya Gorodov Gosttroya RSFSR) previó varias líneas de tranvía rápido (Fig. 15, 16 y 17). Ello se justificaba por una extensión del territorio urbano de sur a norte de unos $30 \mathrm{~km}$ y por ampliar su superficie desde 83.000 ha hasta 132.000 ha (Archivo Estatal de la región de Yaroslavl, 1969). La longitud de las líneas debía crecer significativamente hasta $54 \mathrm{~km}$, de los cuales $42 \mathrm{~km}$ debían ser de tranvía rápido (alrededor del 78\%). La longitud media de los viajes en tranvía era de alrededor de 5,8 $\mathrm{km}$ y debería aumentar notablemente (Lengiprogor, 1971). A pesar del planteamiento de desarrollo tranviario, se preveía que los autobuses debían hacerse cargo del 38\% de los viajes (142 millones de pasajeros al año) frente al 30\% de los tranvías (113 millones). La velocidad de servicio debía ser de 30 $\mathrm{km} / \mathrm{h}$ para poder lograr el tiempo máximo de viaje de 45 min (Lengiprogor, 1971). A pesar de estas ideas definidas en el Plan Urbano, el necesario Esquema Complejo de Transporte (Kompleksnaya Transportnaya Skhema) no fue aprobado hasta 1977. Este desfase propició, de nuevo, que las decisiones sobre el tranvía entre 1971 y 1977 se tomaran a nivel local.

ACE, 16 (4.6) CC BY-ND 3.0 ES | UPC Barcelona, España | Los tranvías en los países del socialismo real de los años 18 1960: de la crisis al impulso. DOI: http://dx.doi.org/10.5821/ace.16.46.9260 
Figura 14. La calle Sovetskaya en el centro de la ciudad en 1966: eliminación de línea tranviaria

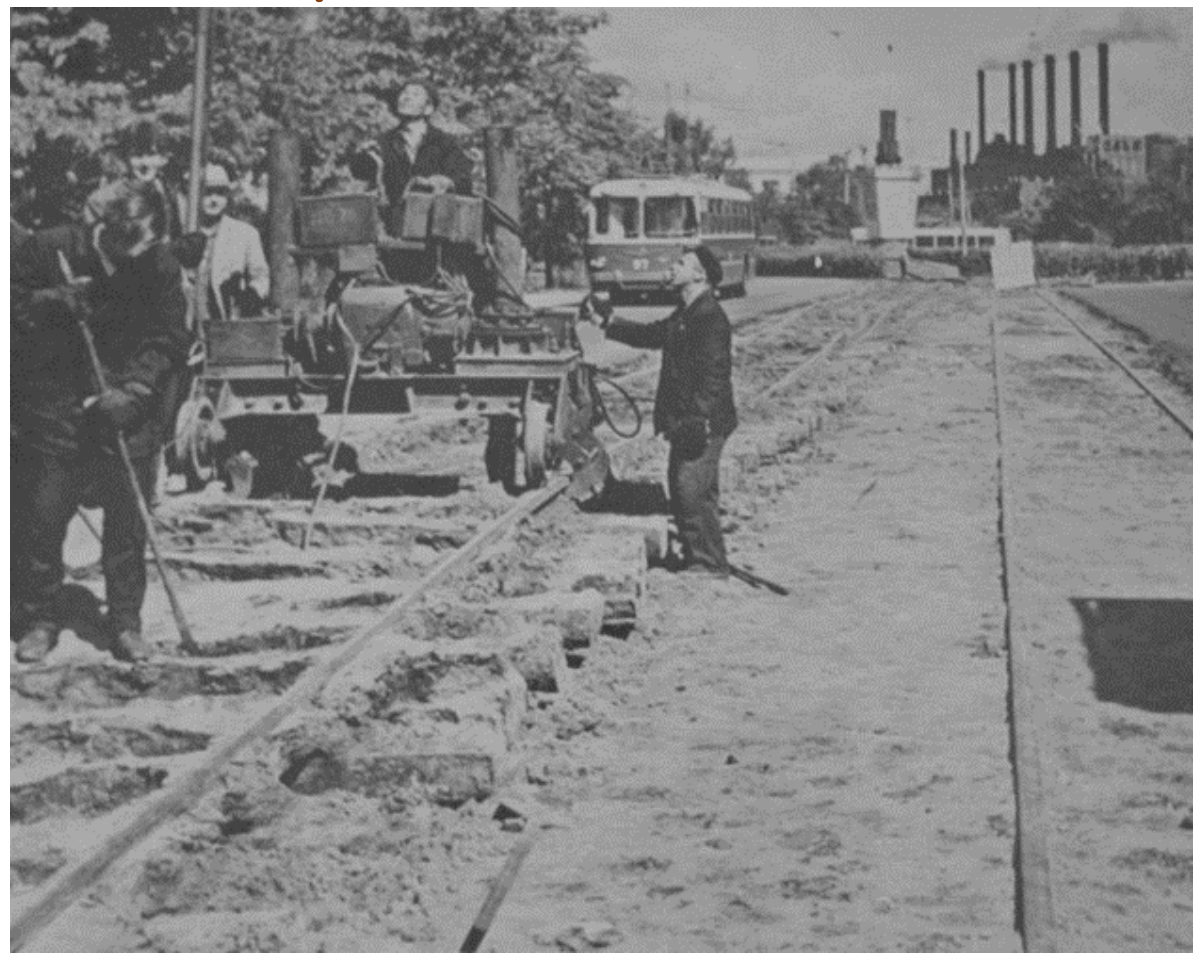

Fuente: Museo YarGET

Los proyectos de nuevas áreas residenciales consideraron la conveniencia de la implantación del tranvía siguiendo las directrices definidas en el Plan General Urbano. Durante la construcción de las líneas en el área residencial Bragino, en el norte de la ciudad, se reservó el espacio central de la calle principal para el tranvía rápido. Sin embargo, por la pretensión de mantener la representatividad de la avenida existente, se decidió desplazar el tranvía a las calles secundarias (Kovalev, 2005), (Fig. 18). Como resultado, el tranvía rápido fue introducido forzadamente en calles consolidadas que no estaban diseñadas para ello (Fig. 19).

Las decisiones locales prevalecieron sobre los planes urbanos y de transporte controlados por instancias superiores, lo que se dio por la carencia de inspección estatal. En los archivos se puede encontrar información sobre un Consejo de Ministros de la URSS de 1963 que subrayaba el problema de las decisiones locales, donde los ayuntamientos eliminaban las líneas sin ninguna explicación ni estudio previo de tráfico: "Hay casos en que los comités ejecutivos de los consejos locales de diputados de los trabajadores retiran y trasladan de forma totalmente irrazonable las líneas de tranvía, sustituyéndolas por otros medios de transporte con una capacidad de transporte más pequeña" (GAE, 1963, p. 13).

Por lo visto, esta actitud se mantuvo también en los años setenta, excusada en la carencia de recursos financieros estatales para que los ayuntamientos desplegaran líneas tranviarias. Pervivió, en fin, una actitud contraria al tranvía, considerado como un medio de transporte o bien obsoleto o bien caro.

ACE, 16 (4.6) CC BY-ND 3.0 ES | UPC Barcelona, España | Los tranvías en los países del socialismo real de los años 


\section{ACE Architecture, City and Environment}

Figuras 15 y 16. Plan General Urbano y Plan Preliminar de Transporte de Yaroslavl, 1971
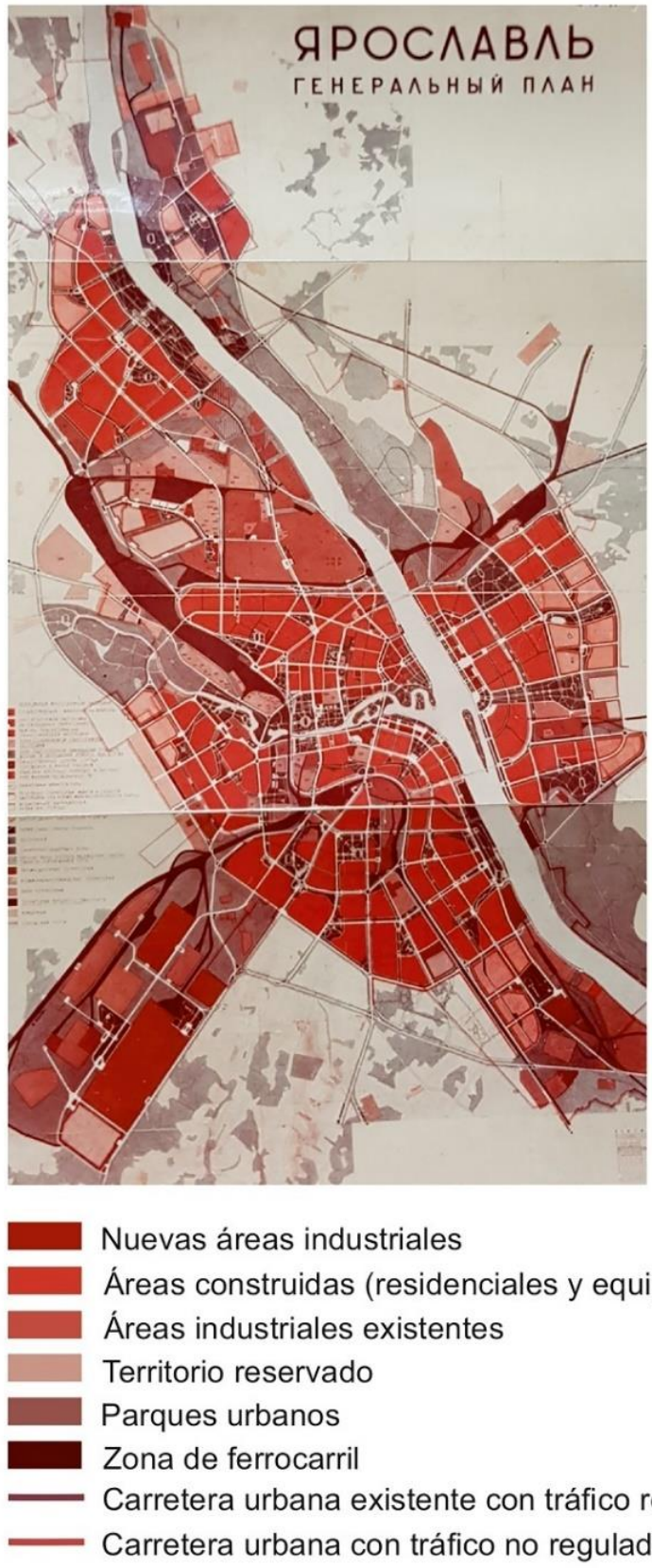

Nuevas áreas industriales

Áreas construidas (residenciales y equipamientos)

Áreas industriales existentes

Territorio reservado

Parques urbanos

Zona de ferrocarril

Carretera urbana existente con tráfico regulado

Carretera urbana con tráfico no regulado

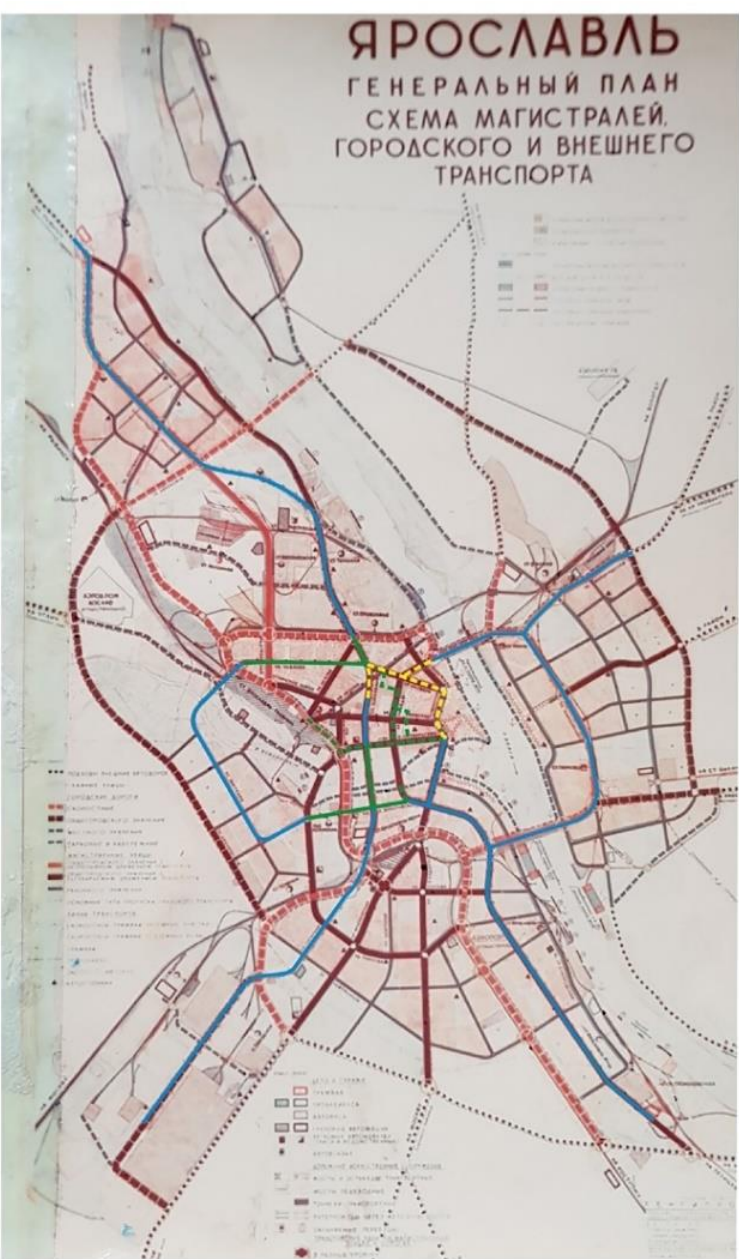

Carretera urbana rápida

Carretera urbana planeada

Carreteras locales

Líneas tranviarias existentes

- Líneas para eliminar

Líneas en túnel

Nuevas líneas tranviarias

(1) $01 \mathrm{~km}, \quad 5 \mathrm{~km}$

Nota: A la izquierda, el Plan General Urbano de Yaroslavl de 1971 elaborado por el Instituto Lengiprogor. A la derecha, el Plan Preliminar de Transporte de Yaroslavl (en el seno del Plan General Urbano), también formado en 1971 por el Instituto Lengiprogor. En verde continuo, las líneas tranviarias existentes; en verde discontinuo, las líneas tranviarias a eliminar; en azul las nuevas líneas tranviarias planteadas por el plan; en amarillo discontinuo, los tramos tranviarios subterráneos. Se puede apreciar una red escasa del tranvía existente con relación al significativo desarrollo de nuevas líneas tranviarias en las áreas periféricas. Fuente: Lengiprogor (1971) Generalnii Plan goroda Yaroslavl, Archivo de Departamento de Arquitectura y de Relaciones de Suelo de la ciudad de Yaroslavl. 
Figuras 17. Esquema del crecimiento urbano de Yaroslavl y de la propuesta de tranvía rápido

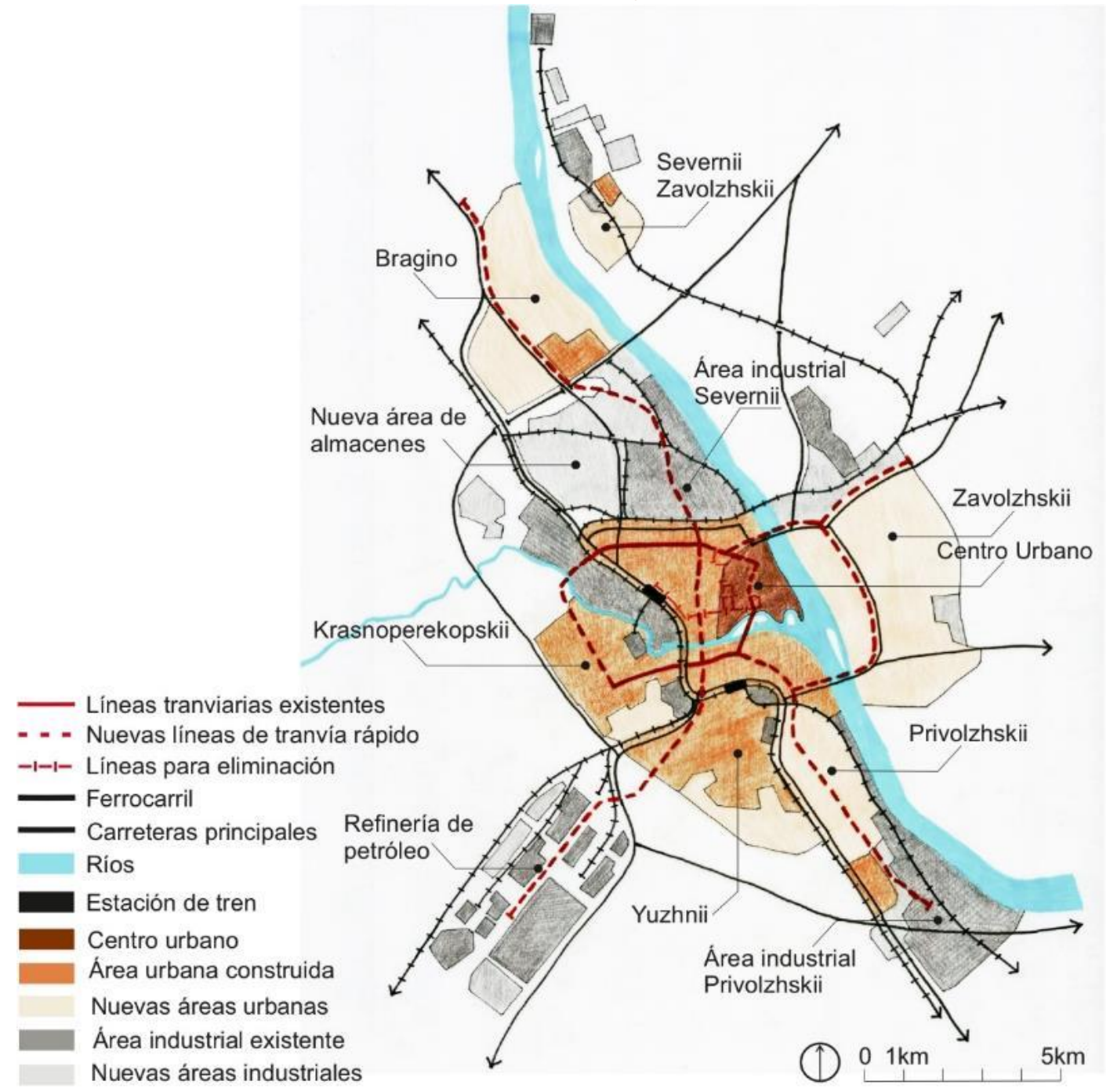

Nota: Se previó una gran extensión de las líneas tranviarias, a pesar de ello, la densidad de la red fue baja y algunas áreas importantes quedaron sin conexión.

Fuente: Elaboración propia a partir del plano de la ciudad existente de 1970, el Plan General Urbano y su Esquema de Transporte de 1971.

Una explicación complementaria para entender la eliminación del tranvía pudo haber sido ser la resolución de 1966 del Ministerio de Economía Urbana de la República Socialista Federativa Soviética de Rusia (RSFSR) denominada "Sobre el desarrollo prospectivo del transporte público urbano para el período 1966-1975" (Perspektivnoe razvitie gorodskogo obshestvennogo transporta 1966-1975), donde se preveía "el desarrollo restringido de los tranvías y un desarrollo extremadamente intenso de trolebuses" (Archivo Estatal de Rusia -GARF-, 1966, 3). Así, para las ciudades con tamaño de 100.000 a 250.000 habitantes, se concebía un 60\% del tráfico de pasajeros en autobuses y un 37\% en transporte eléctrico; para las ciudades de 250.000 a 1 millón de habitantes, un 50 \% en autobús y un $43 \%$ en transporte eléctrico, y solo para las ciudades de más de 1 millón el transporte eléctrico tenía prioridad con un $60 \%$ frente al 30\% en autobuses. Sin duda, estas previsiones influyeron en los porcentajes finales en todo el país, con un 55\% de autobuses y un 35\% de transporte eléctrico (GARF, 1966).

ACE, 16 (4.6) CC BY-ND 3.0 ES | UPC Barcelona, España | Los tranvías en los países del socialismo real de los años 


\section{ACE Architecture, City and Environment}

Asimismo, esta resolución dejó claro que sólo en las grandes ciudades los tranvías y trolebuses (transporte eléctrico) debían ser el principal medio de transporte, mientras que en el resto debían serlo los autobuses. Y debe tenerse en cuenta que el transporte eléctrico privilegiaba las ventajas de los trolebuses por su menor coste en construcción de vías, su funcionamiento más silencioso y su mejor maniobrabilidad. Así, hasta el año 1975 se decidió incrementar el tráfico de pasajeros en trolebús hasta un 22\%, y reducir el tranviario hasta un 18\% (GARF, 1967). De este modo, en el Yaroslavl de los años 1960 se redujo la infraestructura tranviaria. La ratio de pasajeros en tranvía pasó de un $57,6 \%$ en 1960 a un 41,5\% en 1965, un 34\% en 1967 y un 26,5\% en 1969. Por el contrario, la ratio de pasajeros en trolebús y autobús llegó a un 36,9\% y un 36,6\% en 1969 (GARF, 1972b).

Figura 18. La avenida Leningradskii a finales de los años setenta con trolebuses y autobuses

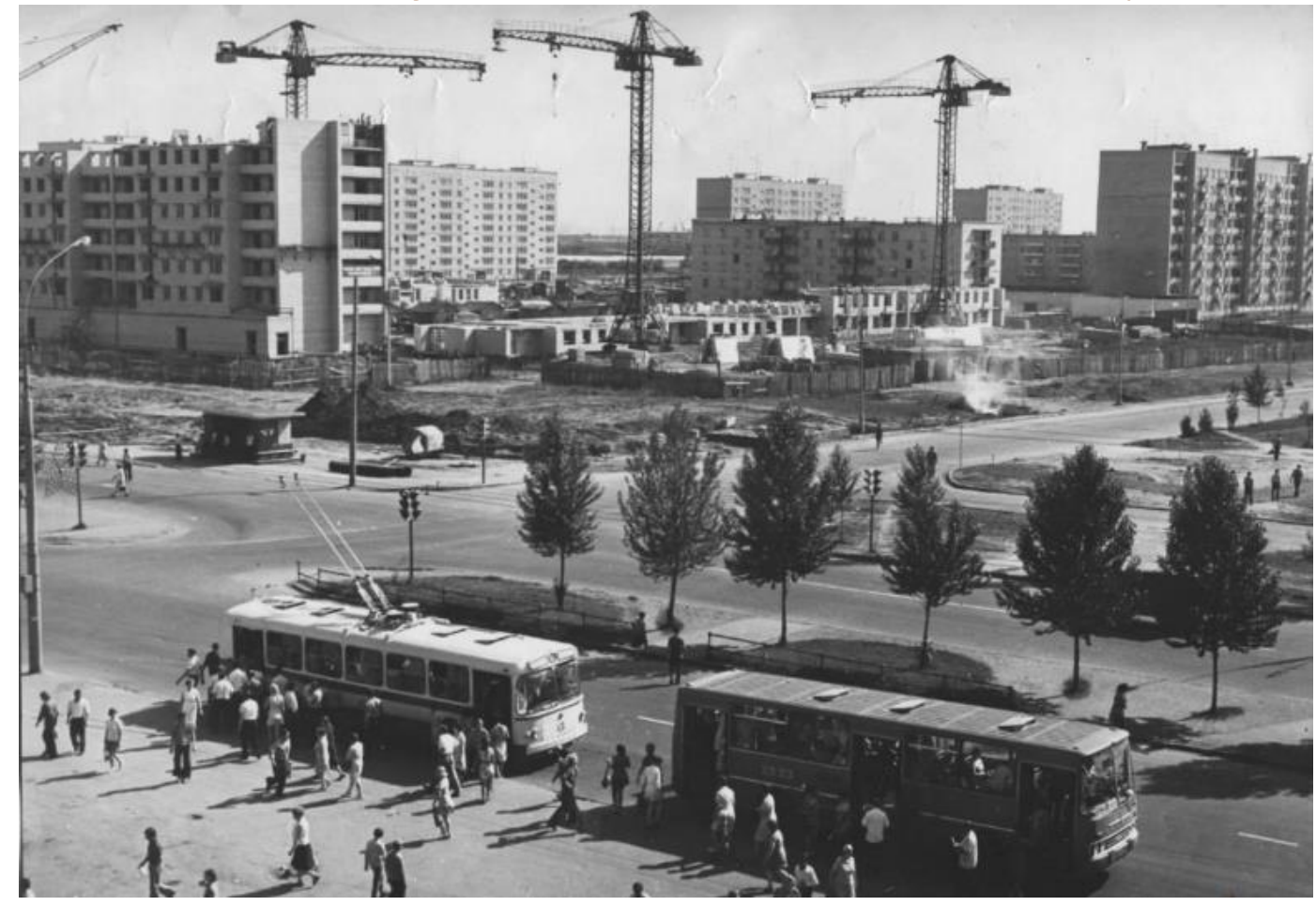

Fuente: www.yargid.ru, fotografía de Zinaida Shemetova

A finales de los años sesenta y principios de los setenta, con el crecimiento del territorio urbano y el deterioro de la accesibilidad de las áreas periféricas de la ciudad, en las instancias estatales se empezó a pensar en la necesidad del tranvía rápido. La preocupación principal residía en las conexiones de las áreas residenciales con las áreas industriales, mientras que su importancia para aliviar la congestión del tráfico automovilístico en el centro de la ciudad seguía sin ser apreciada.

En la evaluación del Esquema Complejo de Transporte de 1973 realizada por la comisión técnicoeconómica del Comité Estatal de Planificación de la República Rusa (Gosudárstvenny Komitet po Planírovaniyu, Gosplan RSFSR), fue destacada la preocupación de los expertos por el escaso desarrollo del transporte público en la ciudad, con pocos tranvías no solo en la realidad existente sino también en el plan. Según el Consejo de expertos técnicos y económicos (GARF, 1972a, p. 3) respecto del tranvía rápido en Yaroslavl: "En la actualidad, en Yaroslavl no sólo se ha suspendido recientemente el desarrollo de este poderoso medio de transporte después del metro, sino que incluso la muy débil red de líneas de tranvía que existía anteriormente está en proceso de reducción”.

ACE, 16 (4.6) CC BY-ND 3.0 ES | UPC Barcelona, España | Los tranvías en los países del socialismo real de los años 22 1960: de la crisis al impulso. DOI: http://dx.doi.org/10.5821/ace.16.46.9260 


\section{ACE Architecture, City and Environment}

E-ISSN 1886-4805

Figura 19. Tranvía rápido del área residencial Bragino en la calle secundaria Trufanova

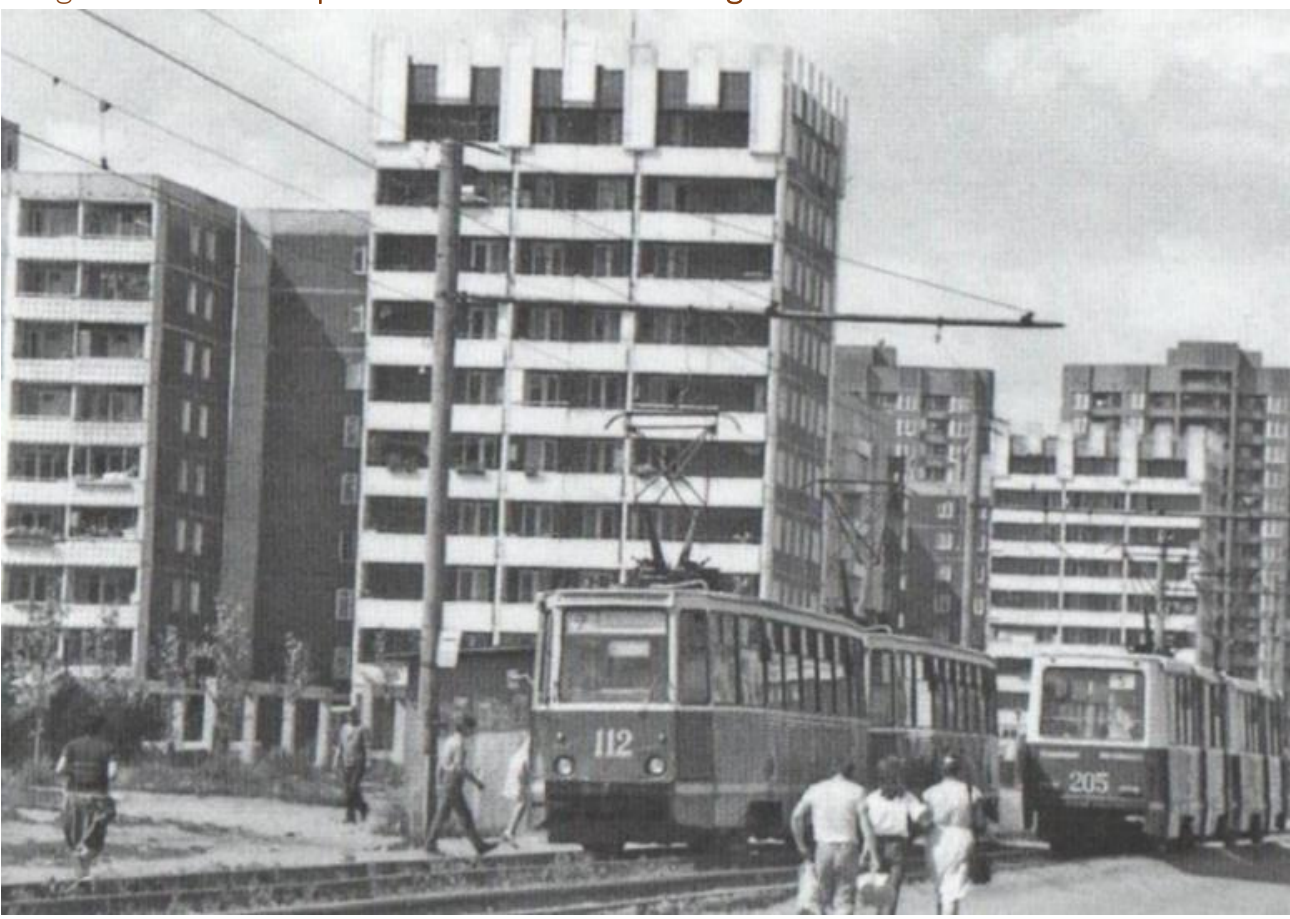

Fuente: Tumanov, A. (2014) Dzerzhinskii raion. Sobitiya i lyudi, Yaroslavl, Yarnovosti, 240.

El desarrollo del sistema tranviario se justificó sobre todo por la configuración alargada y las grandes distancias largas en una ciudad básicamente industrial. En el Plan de 1973 algunas áreas residenciales como la de Zavolzhskii en el este y la gran área industrial del noroeste quedaron sin solución tranviaria. Una de las conclusiones de los expertos del Gosplan fue complementar el plan con nuevas líneas hacia estas áreas (GARF, 1972a). El experto en transporte E. V. Ovechnikov subrayaba también la situación extraña de su eliminación en la ciudad (GARF, 1972b, 17): "Yaroslavl tiene una forma alargada rectangular de $29 \mathrm{~km}$. El desarrollo del transporte por tranvía no ha sido implementado, sino que, por el contrario, recientemente el tranvía ha disminuido, a pesar de que la ciudad está obteniendo un gran desarrollo en términos de territorio y de población. Los servicios de transporte urbano de pasajeros no pueden considerarse satisfactorios."

A pesar de ello, no hubo estudio ni proyecto general de tranvía rápido. Sus criterios técnicos no fueron ni siquiera definidos. Solo se realizó un elemento característico: la plataforma separada de las calles (Kovalev, 2005). Otras características habitualmente requeridas al tranvía rápido, como las mencionadas por Ovechnikov (intersecciones en diferentes niveles, pasos peatonales en túneles, etc.), no se materializaron (GARF, 1972b). La construcción del tranvía rápido se hizo con poco criterio, ajustando las líneas al área urbana ya construida. No hubo espacio reservado para el tranvía ni en las calles ni en los puentes y no fue posible desarrollar velocidades elevadas. Así, no se pudo crear un sistema coherente, de modo que solo sirvió, y de manera poco eficaz, para aumentar la capacidad de transporte de pasajeros.

En definitiva, tanto en la planificación del transporte público colectivo como en las grandes decisiones de construcción de la ciudad, se hicieron planteamientos de corto plazo, y los criterios sociales y medioambientales ni siquiera fueron considerados. El tranvía rápido recibió de hecho un desarrollo decisivo en las ciudades más grandes, que fueron los grandes centros industriales y las capitales territoriales, mientras que las ciudades medianas, con menor tamaño e importancia política, como era el caso de Yaroslavl, no tuvieron tanta atención por el Estado en el desarrollo, control y

ACE, 16 (4.6) CC BY-ND 3.0 ES | UPC Barcelona, España | Los tranvías en los países del socialismo real de los años 23 1960: de la crisis al impulso. DOI: http://dx.doi.org/10.5821/ace.16.46.9260 
financiación de proyectos de tranvía rápido. La tardanza en la implementación de planes urbanos y de transporte, las decisiones locales contra el desarrollo del tranvía y las dificultades estatales de inversión condicionaron un desarrollo débil del tranvía rápido, resultando unas intervenciones escasas, poco coherentes y discontinuas.

\section{Resultados}

Con el análisis de los dos casos se comprueba tanto las diferencias como las similitudes en la planificación del sistema tranviario en dos ciudades medianas industriales de dos países europeos de régimen comunista. Una de las pocas coincidencias es el inicial mantenimiento relativo de las líneas existentes con el objetivo de conectar las áreas industriales, en mayor proporción y mejor cualidad en Ostrava.

En cuanto a las diferencias, destaca la divergencia en las decisiones de elección de los medios de transporte público. En el caso de Yaroslavl en los años sesenta, se proporcionó una ratio mayor al autobús y al trolebús, mientras que las líneas tranviarias se eliminaron o se mantuvieron en las direcciones donde no molestaban el tráfico viario. Ello se explicaba por la escasa financiación estatal, la opinión negativa de las autoridades locales sobre el tranvía y el escaso control estatal sobre la implementación de sus decisiones. En el caso de Ostrava, desde el principio el tranvía fue elegido el medio principal de transporte público, mientras que autobús y trolebús tuvieron un papel complementario. El tranvía se relacionaba directamente con las conexiones entre las áreas industriales y residenciales. La unanimidad de la solución tranviaria y el acuerdo entre las autoridades locales y estatales llevaron tanto el mantenimiento del tranvía como a su modernización temprana.

Una segunda diferencia se relaciona con la diferente implementación de la idea de planificación integrada. En Yaroslavl, el Plan General de Transporte se realizó después de un Plan General Urbano con escasa información en transporte, lo que dificultó la coordinación de las soluciones de planificación. Además, el estudio de transporte realizado durante la realización del Plan General Urbano no reflejaba las opiniones de los especialistas de tráfico, del mismo modo que sus recomendaciones posteriores sobre el tranvía no fueron tenidas en cuenta. Por su parte, en Ostrava tampoco hubo una planificación urbana y de transporte temporalmente integrada, a pesar de lo cual se hizo un esfuerzo a nivel nacional y local para coordinar las soluciones del plan de zonificación y del proyecto de tranvía rápido.

Una diferencia más entre los dos casos responde al condicionante, importante, de tener la posibilidad de disponer del material rodante necesario. En Ostrava, desde mediados de los años sesenta, ya circulaban los modelos T2, T3 y K2, que permitieron incrementar significativamente la capacidad de transporte de pasajeros. En Yaroslavl, y para toda la URSS, sin embargo, hubo restricciones técnicas y económicas para el desarrollo del material rodante. Al principio de los años setenta en la URSS se carecía de los modelos de tranvías que funcionaban con el sistema de múltiples unidades y había dificultades para disponer de los modelos de Tatra, que se enviaban prioritariamente a las ciudades más grandes. Todo ello aumentó la incertidumbre de las autoridades estatales en la decisión sobre la elección del tranvía como medio principal de transporte público.

Por último, hubo diferencias de planteamiento técnico y pensamiento entre los planificadores y los políticos de ambas ciudades. El modelo urbano fragmentado de Ostrava generaba dificultades en la comunicación. En relación con ello se había desarrollado una red tranviaria desarrollada que tradicionalmente se valoraba como una herramienta para superar las distancias. Las nuevas ideas de los años setenta contra el crecimiento del tráfico automovilístico reforzaron el papel del tranvía en Ostrava. Por otro lado, Yaroslavl en los años sesenta tuvo un modelo urbano bastante compacto,

ACE, 16 (4.6) CC BY-ND 3.0 ES | UPC Barcelona, España | Los tranvías en los países del socialismo real de los años 
lo que potenció en principio la idea de suficiencia de los servicios de trolebuses y autobuses. El nuevo Plan General Urbano en 1969 propuso el crecimiento residencial e industrial, acompañado de un cambio de modelo urbano, lo que precisaba la implantación del tranvía rápido. Esta condición no se realizó simultáneamente a la construcción de las nuevas áreas residenciales. Se tardó bastante en implementarla, no solo por las dificultades económicas o técnicas, sino porque las ideas de los años sesenta mantuvieron una continuidad extemporánea, asentándose la expulsión tranviaria de las calles más importantes y del centro, así como la posibilidad de seguir como antes con los modos viarios de transporte público.

De esta comparación se puede concluir que Ostrava representa un caso de coincidencia de varios factores que resultaron ser claves en la importante implementación del sistema tranviario. Primero, la política nacional de transporte público orientada a la modernización del tranvía, reafirmada por las autoridades locales, por los planificadores y por la existencia de una industria tranviaria potente. Segundo, el desarrollo de áreas residenciales e industriales en la periferia suburbana de la ciudad desde principios de los años cincuenta, lo que intensificó la importancia del tranvía por sus capacidades mayores para el movimiento de pasajeros. Tercero, la solución del tranvía rápido se reforzó con argumentos no ya solo económicos, sino también sociales y ambientales. Por el contrario, Yaroslavl muestra un caso en el que, a pesar de una insatisfactoria comunicación entre áreas urbanas, las autoridades locales se resistieron a mantener el tranvía convencional y a implementar el tranvía rápido. Si en los años sesenta ya casi no era posible justificarlo en la nominalista política de contención del desarrollo urbano, en los años setenta, a pesar de tener previsto el sistema de tranvía rápido, este tardó en implementarse debido a una política estatal poco definida en el desarrollo real del transporte público urbano, un nivel bajo de organización del proceso de planificación y la oposición de las autoridades locales, que se intensificaba con la prevalencia de los criterios de eficiencia de la planificación de transporte del Movimiento Moderno.

\section{Conclusiones}

Los dos casos extremos entre los muchos posibles hacen posible comprender algo que desde Occidente no ha sido fácilmente apreciable y que va en contra de la idea de que todo estaba planificado y sin disparidad de criterios en el "bloque comunista": la variedad de las aproximaciones y propuestas en la planificación tranviaria entre 1950 y 1980.

La crisis del sistema tranviario en la posguerra solo cambió en los años sesenta para verse desarrollado después, sobre todo mediante el tranvía rápido de los años setenta. En Ostrava, como en bastantes ciudades de la RSC, el tranvía fue cuidado y mejorado en cuanto se pudo, mientras que, en Yaroslavl, como en otras ciudades de la URSS y de otros países de Europa Oriental, el tranvía fue inicialmente orillado para ver renacer su función solo a partir de los años setenta.

Fue con el crecimiento urbano de los setenta en adelante cuando el tranvía rápido se convirtió en una solución viable y factible, aun a pesar de que la solución deseable fuese el metro ligero. La diferencia principal entre tranvía rápido y metro ligero estaba en los estándares de construcción de vía y en el nivel de separación en las intersecciones. Según las condiciones y posibilidades locales fueron adaptándose los criterios técnicos, creando sistemas mixtos. En la política de transporte de las ciudades europeas del socialismo real, el tranvía no siempre fue considerado como el medio principal de transporte público colectivo. La consideración de su papel funcional guardaba relación tanto con las cuestiones relacionadas con la modernidad urbana como con la posibilidad o imposibilidad de la modernización de su infraestructura y material rodante. El papel del tranvía rápido

ACE, 16 (4.6) CC BY-ND 3.0 ES | UPC Barcelona, España | Los tranvías en los países del socialismo real de los años 25 1960: de la crisis al impulso. DOI: http://dx.doi.org/10.5821/ace.16.46.9260 
también se vio incrementado con el aumento considerable de las necesidades de movilidad entre las áreas concentradas de trabajo y las de residencia, y en los casos de una estructura urbana fragmentada y alargada, en los que las distancias eran muy grandes.

En los años setenta, el papel del tranvía se intensificó con la consideración del tráfico suburbano en el desarrollo del sistema de transporte. La política de transporte en la RSC, por otro lado, constructora de los tranvías mejor considerados en los países comunistas (la fábrica ČKD Tatra), fue orientada en general a la modernización de los sistemas tranviarios. En la URSS, sin embargo, durante los años sesenta y una parte de los años setenta, la política más usual para las ciudades medianas fue el desarrollo intensivo de los trolebuses. La implantación del tranvía rápido para las ciudades medianas se asentó solo desde finales de los años setenta.

Se puede concluir que durante el periodo de estudio en los países europeos del socialismo real no hubo una política generalizada de planificación del transporte público urbano, contra lo que se ha pensado habitualmente. Fue difícil llegar a unos principios extendidos por tener como principal prioridad la economía nacional y la capacidad productiva. Las diferencias entre países se dieron en la interpretación política del papel del transporte urbano, en la organización del sistema de planificación, en el nivel de desarrollo técnico y provisión de material rodante de tranvía y también en las aproximaciones profesionales y las actitudes políticas en la planificación del tráfico. Estas políticas de transporte público, realizadas durante un periodo de desarrollo económico importante, fueron decisivas en la consolidación de la red tranviaria en las ciudades de los países de régimen comunista y tuvieron cierta continuidad posteriormente.

\section{Agradecimientos}

La investigación de la que forma parte este artículo se inserta en el proyecto UrbanHist, el cual ha recibido financiación del programa de investigación e innovación “Horizon 2020" de la Unión Europea en virtud del acuerdo de subvención Marie Skłodowska-Curie no 721933. Los autores agradecen además los comentarios y las sugerencias de los revisores.

\section{Autoría}

El artículo se inscribe en la investigación doctoral de la primera autora: "Trams in Socialist Urban Planning in the 1960s and 1970s: Urban and Transport Models in the GDR, the CSR and the USSR". El segundo autor es uno de sus directores de tesis. De este modo, la primera autora ha realizado el proceso de documentación archivística, la revisión bibliográfica, el apartado de resultados y la revisión del artículo. El segundo autor ha realizado el diseño metodológico. Ambos se han hecho cargo conjuntamente del marco teórico, la redacción y las conclusiones.

Conflicto de intereses: Los autores declaran que no hay conflicto de intereses.

\section{Bibliografía}

Akademiya Arkhitekturi SSSR. (1956). Planirovka i Zastroika Gorodov. Moskva, URSS: Gosudarstvennoe Izdatel'stvo po Stroitel'stvu i Arkhitekture.

Archivo Municipal de Ostrava. (1965). Směrné Uzemní Plan Mesta Ostravy, Revize. Národní výbor města Ostravy, Krajský Projektový Ustav “Stavo Projekt” - Ostrava, Ostrava, República Checa.

ACE, 16 (4.6) CC BY-ND 3.0 ES | UPC Barcelona, España | Los tranvías en los países del socialismo real de los años 
Archivo Municipal de Ostrava. (1973). Generel Dopravy - Ostrava, Čistopis Návrhu. Utvař Dopravního Inženýrství Města Ostravy (en adelante UDIMO), Dopravoproject Brno, Ostrava, República Checa.

Archivo Municipal de Ostrava. (1974a). Dlouhodobý Výhled Rozvoje Dopravy v ČSR do roku 1990. Národní výbor města Ostravy, Ministerstvo Vnútra ČSR (2208), Ostrava, República Checa.

Archivo Municipal de Ostrava. (1974b). Studie Přehodnocení Koncepce MHD v Ostravě. UDIMO, Inženýrské Služby ČsSı v Brně, Ostrava, República Checa.

Archivo Municipal de Ostrava. (1976). Rychlá Hromadná Osobní Doprava v Ostravské Aglomeraci. UDIMO, Ostrava, República Checa.

Archivo Municipal de Ostrava. (1977). Výstavba Systému Rychlé Tramvaje v Brně a Ostravě. Návrh pro jednání vlády ČSR, UDIMO (66), Ostrava, República Checa.

Archivo Municipal de Ostrava. (1978a). Záznam, výrobního výboru k úkolu II - 4.01/78 - Rešení rychlé tramvaje v príměstských oblastech města Ostravy. UDIMO, Ostrava, República Checa.

Archivo Municipal de Ostrava. (1978b). Návrh usnesení Vlády ČSR, Výstavba Systému Rychlé Tramvaje v Brně a Ostravě. UDIMO, Vláda ČSR, Ostrava, República Checa.

Archivo Municipal de Ostrava. (1978c). Návrh usnesení Vlády ČSR. Pracovní material. Dưvodová Zpráva. O Zajišténi Připravy a Realizaci Systému Rychlé Tramvaje v Brně a Ostravě. UDIMO, Vláda ČSR, Ostrava, República Checa.

Archivo Municipal de Ostrava. (1978d). Komplexní řešeni dopravy v Ostravské aglomeraci, UDIMO, Ostrava, República Checa.

Archivo Municipal de Ostrava. (1979) Útvar hlavního architekta Magistrátu města Ostravy. Ostrava, República Checa.

Archivo Estatal de la República Checa. (1966). Koncepce rozvoje mestské hromadné dopravy do roku 1980. Ministerstvo Dopravy ČSSR, Praga, República Checa.

Archivo Estatal de Rusia (Gosudarstvenii Arkhiv Rossiskoi Federatcii, en adelante GARF). (1963) Ob uluchshenii obsluzhivaniya naseleniya gorodskim transportom (Sobre la mejora de servicio de transporte urbano). Proyecto de Resolución del Consejo de ministros de la URSS (5, 1, 69), Moscú, Rusia.

Archivo Estatal de Rusia, GARF. (1966). Dokumenti po Perspecktivnomu Razvitiyu Gorodskogo Obshestvennogo Transporta 1966-1975, (Documentos sobre el desarrollo prospectivo de transporte público colectivo). Ministerio de Economía Comunal (Ministertvo Zhilishno-Kommunalnogo Khozyaistva), (A-314, 3, 8103), Moscú, Rusia.

Archivo Estatal de Rusia, GARF. (1967). Perepiska CK KPSS i SMRSFSR i SSSR po voprosam tramvainotrolleibusnogo khozyaistva, (Correspondencia entre el Comité Central KPSS y Consejo de ministros de RSFSR y de SSSR sobre las cuestiones de desarrollo de tranvía y trolebuses). Tsentralnii komitet KPSS y Sovet Ministrov RSFSR, (A-314, 3, 8589), Moscú, Rusia.

Archivo Estatal de Rusia, GARF. (1972a). Materiali po rassmotreniyu kompleksnoi skhemi razvitiya vsekh vidov gorodskogo passazhirskogo transporta Yaroslavlya, (Materiales sobre la evaluación de esquema complejo de transporte de todos los medios de transporte urbano de pasajeros en Yaroslavl). Gosplan RSFSR, Sovet Tekhniko-ekonomicheskoi Ekspertizi, (A-262, 16, 1431), Moscú, Rusia.

ACE, 16 (4.6) CC BY-ND 3.0 ES | UPC Barcelona, España | Los tranvías en los países del socialismo real de los años 
Archivo Estatal de Rusia, GARF. (1972b). Zaklyuchenie po rabote vypolnennoi Lengiprogorom v 1972 godu, Kompleksnaya skhema razvitiya vsekh vidov gorodskogo passazhirskogo transporta $v$ gorode Yaroslavle, $v$ chasti skorosnogo tramvainogo transporta. Doklad Ovechnikova, E. V., (A-262, 16, 1431), Moscú, Rusia.

Archivo Estatal de Economía de Rusia, (Gosudarstvennii Arkhiv Ekonomiki, en adelante GAE). (1963). Proyecto de resolución del Consejo de ministros de SSSR sobre la mejora de servicio de transporte urbano, (Proekt Postanovleniya Soveta Ministrov SSSR ob uluchshenii obsluzhivaniya naseleniya gorodskim transportom). Consejo de ministros de la URSS, (5, 1, 69), Moscú, Rusia.

Archivo Estatal de Economia de Rusia, GAE. (1963-1988). Materili, otcheti, zaklyucheniya, spravki $i$ drugoe po obsledovaniyu planirovki i zastroiki goroda Yaroslavlya. Gosstroi RSFSR, (5, 5, 254), Moscú, Rusia.

Archivo Estatal de la Región de Yaroslavl. (1969). Protokol i stenogramma zasedniya po generalnomu planu goroda Yaroslavlya. Gosstroi RSFSR, (P-872, 5, 35), Yaroslavl, Rusia.

Archivo Estatal de la Región de Yaroslavl. (1972). O plane razvitiya mestnogo khozyaistva oblasti na 1971-1975 godi. Yaroslavskoe tramvaino-troleibusnoe upravlenie, (P-1358, 1, 265), Yaroslavl, Rusia

Lengiprogor. (1971) Generalnii Plan goroda Yaroslavl. Archivo de Departamento de Arquitectura y de Relaciones de Suelo de la Ciudad de Yaroslavl, Yaroslavl, Rusia.

Archivo del Museo Yarget. Colección de fotografías. Yaroslavl, Rusia.

Barton, M. (1975). Ostrava 1945-1975. Ostrava, Checoslovaquia: Útvar Hlavního Architekta Města Ostravy.

Bennet R. y Elmberg C. (1977). Priority for Surface Public Transport. En Proceedings of the 42nd International Congress of Public Transport (pp. 20-30). Montreal, Canadá: UITP.

Bolonenkov, G. V. (1972). Skorostnoi Obshestvennii Transport Krupnogo Goroda. Moskva: Gosgrazhdanstroi SSSR.

Boquet, Y. (2017). The renaissance of tramways and urban redevelopment in France. Miscellanea Geographica - Regional Studies on Development, 21(1), 5-18. DOI: http://dx.doi.org/10.1515/mgrsd-2017$\underline{0005}$

Bordukov, I. V. (1974). O razrabotke kompleksnikh skhem razvitiya gorodskogo passazhirskogo transporta. Kiev, URSS: Budivelnik.

Brown, R. G. (1966). The integration of Metropolitan Transportation Planning with a Comprehensive Development Policy: A Coordinated Approach (Tesis master). University of British Columbia, Canadá.

Crouch, M. (1979). Problems of Soviet Urban Transport. Soviet Studies, 31(2), 231-256. Recuperado de https://www.jstor.org/stable/150102

Efremov, I. S. (1969). Trolleibusi. Moskva: Vysshaya Shkola.

Hall, P. (1976). Kadry i obrazovanie. En P. Cowan. (Ed.), Buduchee planirovki. Trad. Yaroshevskii, B. E., Londrés, Reino Unido: Heinemann.

ACE, 16 (4.6) CC BY-ND 3.0 ES | UPC Barcelona, España | Los tranvías en los países del socialismo real de los años 
Hass Klau, C.; Crampton, G.; Biereth, C. y Deutsch, V. (2003). Bus or Light Rail: Making the Right Choice. Brighton, Reino Unido: Environmental and Transport Planning.

Hass Klau, C.; Crampton, G. y Benjari, R. (2004). Economic Impact of Light Rail: The Results for 15 Urban Areas in France, Germany, UK and North America. Brighton, Reino Unido: Environmental and Transport Planning.

Honzík, A. (1967). Mezinárodní Konference o Vývoji Městské a Př́městské Kolejové Dopravy po roce 1970. Praga, Checoeslovaquia: ČKD Praha.

Hruška, E. (1966). Problémy súčasného urbanismu. Bratislava, Checoslovaquia: Slovenská Akadémia Vied.

Inouye, T. (1966). Urban Transportation and Urban Pattern. En Proceedings of the 27th World Congress of the International Federation for Housing and Planning (pp. 55-71). Tokio, Japón: IFHP.

Ivanov, M. D.; Ponomarev, A. A. y leropolski, B. K. (1977). Tramvainie vagoni T-3. Moskva, URSS: Transport.

Jamieson, G. B.; Mackay, W. K. y Latchford, J. C. R. (1967). Transportation and Land Use Structures. Urban Studies, 4(3), 201-217. Recuperado de https://www.jstor.org/stable/43081054

Jansa, F. (1967). Městské Dráhy Elektrické. Bratislava, Checoslovaquia: Vydavatel'stve technickej literatúry. N. P.

Khitzenko, V. V. (1976). Skorostnoi Tramvai. Leningrad, URSS: Stroiizdat.

Komunistická strana Československa. (1977). 15. sjezd komunistické strany Československa. Praha, Checoslovaquia: Svoboda.

Kovalev, A. D. (2005). Na elektricheskoi tyage. Ocherki Istorii Yaroslavskikh tramvaya i trolleibusa. Yaroslavl, Rusia: Izdatel'stvo Aleksandra Rutmana.

Lehrer, F. (1961). Public Transport within the Framework of Urban General Traffic Plans. En Proceedings of the 34th International Congress of Public Transport (pp. 1-84). Copenhagen, Dinamarca: UITP.

Lehrer, F. (1969). Regional Organization of Transport and Urban Development. En Proceedings of the 38th International Congress of Public Transport (pp. 1-148). Londrés, Reino Unido: UITP.

Leibbrand, K. (1964). Verkehr und Städtebau. Basel y Stuttgart, RFA: Birkhäuser.

McGrath Jr., D. C. (1973). Appropriate Relationships between Comprehensive Planning and Transportation Planning for the 1970s. Transportation, 1(4), 403-418. DOI: https://doi.org/10.1007/BF00172389

Meyer H. H. (1979). Die langfristige Rolle des öffentlichen Verkehrs. En Proceedings of the 43rd International Congress of Public Transport (pp. 1-32). Helsinki, Finlandia: UITP.

Mirás, I. (2005). The Spanish tramway as a Vehicle for Urban Shaping: La Coruña, 1903-1962. Journal of Transport History, 26(2), 20-37. DOI: https://doi.org/10.7227/TJTH.26.2.2

ACE, 16 (4.6) CC BY-ND 3.0 ES | UPC Barcelona, España | Los tranvías en los países del socialismo real de los años 
Mlejnek, V. (1967). Městská hromadná doprava v ČSSR. En Prednášky z celostátního semináře o problémech hromadné dopravy ve větších městech ČsSR (kromě Prahy) (pp. 1-26). Praga, Chesoslovaquia: Československá společnost pro šiření politických a vědeckých znalostí.

Norley, K. (2010). Light rail: the semi-metro concept. 33rd Australasian Transport Research Forum, Canberra, Australia: ACT.

Novák, M. (1982). Doprava a životní prostředí v Ostravě. Ostrava, Checoslovaquia: UDIMO.

Paschetto, A. (1975). Gegenseitige Beeinflussung zwischen öffentlichen Verkehr und der Entwicklung von Stadt und Region. En Proceedings of the 41st International Congress of Public Transport (pp. 1-61). Niza, Francia: UITP.

Passalacqua, A. (2014). Reluctant Capitals: Transport Mobility and Tramways in London and Paris 1830 1950. The Town Planning Review, 85(2), 143-154. https://www.jstor.org/stable/24579234

Peshekerov, P. K. y Bondarevskii, D. I. (1936). Tramvainii Spravochnik. Moskva, URSS: OGIZGostransizdat.

Pithardt, J. K. (1975). Vývoj a Stav Městské Hromadné Dopravy v ČSSR. En Pithardt, J. K.; Thoř, V. y Vandas J. (Eds.), Městská Hromadná Doprava (pp. 10-114). Praga, Checoslovaquia: Společnost Dopravy a Spojů.

Polyakov, A. A. (1953). Gorodskoe Dvizhenie i Planirovka Ulitc. Moskva-Leningrad, URSS: Gosudarstvennoe Izdatel'stvo Literaturi po Stroitel'stvu i Arkhitekture.

Pooley, C. G. y Turnbull, J. (2005). Coping with Congestion: Responses to Urban Traffic Problems in British Cities c. 1920-1960. Journal of Historical Geography, 31(1), 78-93. DOI: https://doi.org/10.1016/i.jhg.2003.08.019

RIBA. (1968). Warning on Traffic and Planning. The Architects' Journal, 147 (25), 1367.

Saprykina, N. S. (2006). Sovetskaya Arkhitektura Yaroslavlya: Realnost i Virtualnost. Yaroslavl, Rusia: YGTU.

Sheinyuk, G. S. (1971). Skorostnoi Tramvai. Moskva, URSS: GOSINTI.

Schmucki, B. (2010). Fashion and Technological Change Tramways in Germany after 1945. Journal of Transport History, 31(1), 1-24. DOI: https://doi.org/10.7227/TJTH.31.1.2

Taplin, M. R. (1984). Light Rail Transit Today. Milton Keynes, Reino Unido: Light Rail Transit Association.

Tennant, K. D. (2017). Profit or utility maximizing? Strategy, tactics and the Municipal Tramways of York, c. 1918-1935. Journal of Management History, 23(4), 401-422. DOI: https://doi.org/10.1108/JMH05-2017-0026

Topp, H. H. (1998). Renaissance of Trams in Germany - Five Case Studies. Proceedings of the Institution of Mechanical Engineers: Journal of Rail and Rapid Transit, Part F, 212(3), 223-233. DOI: https://doi.org/10.1243/0954409981530823

Tumanov, A. (2014). Dzerzhinskii raion. Sobitiya i lyudi. Yaroslavl, Rusia: Yarnovosti.

ACE, 16 (4.6) CC BY-ND 3.0 ES | UPC Barcelona, España | Los tranvías en los países del socialismo real de los años 
Utvař Dopravního Inženýrství Města Ostravy. (1982). Doprava a Životní Prostředí v Ostravé. Ostrava, Checoslovaquia: UDIMO.

Vucnic, V. R. (1972). Light Rail Transit Systems: A Definition and Evaluation, Report Department of Transportation Urban Mass Transportation Administration. Washington, Estados Unidos de América: University of Pennsylvania.

Vucnic, V. R. (2007). Urban Transit. Systems and Technology. New Jersey, Estado Unidos de América: John Wiley \& Sons, Inc.

Výzkumný Ústav Výstavby a Architektury (VúVA), (1979) Zásady a Pravidla Územního Plánování. Brno, Checoslovaquia: VúvA.

Yago, G. (2006). The Decline of Transit. Urban Transportation in German and US Cities 1900-1970. Cambridge, Reino Unido: Cambridge University Press.

Yudin, V. A., Samoilov, D. S. (1975). Gorodskoi transport. Moskva, URSS: Stroiizdat.

Zakopal, D. (1977). Priorita Rychlé Tramvaje v Městské Hromadně Dopravě v Ostravě. En Perspektivy Moderních Tramvaji (pp. 1-18). Praga, Checoslovaquia: Československa Védecko-Technickä Společnost.

Zarecor, K. E. (2013). Infrastructural Thinking: Urban Housing in Former Czechoslovakia from the Stalin Era to EU Accession. En Murphy, E. y Najib, B. Hourani (Eds.), The Housing Question: Tensions, Continuities, and Contingencies in the Modern City (pp. 57-78). Farnham, Canadá: Ashgate.

Zilbertal, A. K. (1932). Tramvainoe khozyastvo. Moskva-Leningrad, URSS: Gosudarstvennoe transportnoe izdatel'stvo.

Zmija, K. (1967). Reshenie Problemi Gorodskogo Transporta $\vee$ Ostrave $\vee$ Budushie Gody. En International Conference - Development of Urban and Suburban Transport in the period after the 1970 (pp. 1-50). Praga, Checoslovaquia: ČKD Praha.

Zmija, K. (1985). Doprava a Komunikace v Ostravě. En Bartoš, J. y Dohnal, M. (Eds), Ostrava: Sborník Př́spěvkư k dějinám a výstavbě města (pp. 289-319). Ostrava, Checoslovaquia: Profil. 